\author{
UNIVERSIDADE DE SÃO PAULO \\ FACULDADE DE ECONOMIA, ADMINISTRAÇÃO E CONTABILIDADE \\ DEPARTAMENTO DE ECONOMIA \\ PROGRAMA DE PÓS-GRADUAÇÃO EM ECONOMIA
}

\title{
Reformas e crescimento: Uma análise da abertura da América Latina na década de 90
}

\author{
Lucas Chang Carvalho Santana \\ Orientador: Prof. Dr. Mauro Rodrigues Jr. \\ Coorientador: Prof. Dr. David Daniel Turchick Rubin
}

São Paulo 
Prof. Dr. Vahan Agopyan

Reitor da Universidade de São Paulo

Prof. Dr. Fábio Frezatti

Diretor da Faculdade de Economia, Administração e Contabilidade

Prof. Dr. José Carlos de Souza Santos

Chefe do Departamento de Economia

Prof. Dr. Wilfredo Fernando Leiva Maldonado

Coordenador do Programa de Pós-Graduação em Economia 


\title{
Reformas e crescimento: Uma análise da abertura da América Latina na década de 90
}

\author{
Dissertação apresentada no Departamento de \\ Economia da Faculdade de Economia, Adminis- \\ tração e Contabilidade da Universidade de São \\ Paulo como requisito da obtenção do título de \\ Mestre em Ciências.
}

Orientador: Prof. Dr. Mauro Rodrigues Jr.

Coorientador: Prof. Dr. David Daniel Turchick Rubin

Versão Corrigida

São Paulo

2021 


\section{Santana, Lucas Chang Carvalho.}

Reformas e crescimento: Uma análise da abertura da América Latina na década de 90 / Lucas Chang Carvalho Santana. - São Paulo, 2021. $77 \mathrm{p}$.

Dissertação (Mestrado) - Universidade de São Paulo, 2021. Orientador: Mauro Rodrigues.

Co-orientador: David Daniel Turchick Rubin.

1. Crescimento Econômico. 2. América Latina. 3. Comércio Internacional. I. Universidade de São Paulo. Faculdade de Economia, Administração e Contabilidade. II. Título. 
Lucas Chang Carvalho Santana

\section{Reformas e crescimento: Uma análise da abertura da América Latina na década de 90}

Dissertação apresentada no Departamento de Economia da Faculdade de Economia, Administração e Contabilidade da Universidade de São Paulo como requisito da obtenção do título de Mestre em Ciências.

Prof. Dr. Mauro Rodrigues Jr.

Orientador

Prof. Dr. Márcio Issao Nakane

Prof. Dr. Pedro Cavalcanti Ferreira

Prof. Dr. Tiago Cavalcanti

São Paulo

2021 



\section{Agradecimentos}

Primeiro gostaria de agradecer a Deus, por ter me dado força, incentivo e alegria durante todo o período do curso de mestrado.

À minha família por todo o suporte e incentivo, principalmente durante minha estadia fora de Salvador. Também pela compreensão durante todo o período que passei focado nos estudos. Particularmente agradeço à minha mãe, Edicira, por todo suporte e apoio durante esse período e ao meu pai, Luciano, por ter me estimulado a seguir uma carreira acadêmica.

Ao meu orientador, Mauro Rodrigues, por toda ajuda, paciência, ensinamentos e conselhos. Tenho certeza que ter sido seu orientando foi uma grande experiência para mim. Agradeço também ao meu coorientador, David Turchick, por sempre estar disponível para me ajudar e me aconselhar e por toda a confiança, muitas vezes acreditando mais em mim do que eu mesmo. Espero que no futuro possa me tornar um pesquisador tão bom quanto os dois.

Aos meu colegas de mestrado, por toda ajuda, companheirismo e aprendizado, principalmente durante meu tempo em São Paulo, me fazendo sentir em casa mesmo longe de Salvador. Agradeço particularmente a Rafael Pereira, com o qual fiz a dupla de ataque mais prolífica do futebol de quarta, e Rodrigo Pacheco, por toda ajuda e conhecimento compartilhado. Também agradeço a Débora Oliveira, Lucas Cardoso, Luccas Assis, Pedro Oliveira e Rafael Oliveira por terem tornado esse curso mais divertido e pelo companherismo durante os momentos mais difíceis.

À minha noiva, Maira Lima, por todo amor, companherismo e compreensão durante todo o período que fiquei afastado dela. Sem sombra de dúvidas, seu constante apoio foi fundamental para que eu conseguisse terminar o curso. Agradeço por tudo.

Finalmente, dedico esse estudo à Fundação de Amparo à Pesquisa do Estado de São Paulo (FAPESP), por ter me concedido uma bolsa de mestrado (número do processo 2019/20424-6), e ao Conselho Nacional de Desenvolvimento Científico e Tecnológico (CNPQ). Pelo suporte financeiro, agradeço às duas instituições. 



\section{Resumo}

Após a crise da dívida de 1982, a maior parte dos países latino-americanos percebeu que uma estratégia de desenvolvimento baseada na substituição de importações causa sérios problemas macroeconômicos. No fim da década de 80 e começo da década de 90, os países dessa região começaram uma série de reformas econômicas no sentido de adotarem políticas pró-mercado e pró-comércio. Entretanto, o alto crescimento esperado com essas reformas não ocorreu. Nesse trabalho, iremos propor um modelo dinâmico de equilíbrio geral para uma melhor compreensão da relação entre comércio internacional e crescimento. O regime de comércio é formulado de maneira similar ao observado na América Latina durante a década de 90, ou seja, uma abertura comercial após um período de políticas protecionistas. Os resultados produzidos pelo modelo são similares aos resultados que foram observados na América Latina após a abertura comercial, que são um baixo crescimento do produto, aumento da produtividade total dos fatores e redução da razão capital-produto.

Palavras-chave: Crescimento Econômico. América Latina. Comércio Internacional. 



\section{Abstract}

After the debt crisis of 1982, the majority of Latin American countries realized that a development strategy based on import substitution causes serious macroeconomic problems. In the late 1980s and early 1990s, countries in this region began a series of economic reforms to adopt pro-market and pro-trade policies. However, the high growth expected from these reforms did not occur. In this paper, we introduce a dynamic general equilibrium model for a better understanding of the relationship between economic growth and international trade. The trade regime is modeled similarly to Latin America's experience during the 1990s, that is, a trade liberalization after a period of protectionist policies. The results produced by the model are similar to the results that were observed in Latin America after trade liberalization, which are a small growth in output, an increase in total factor productivity and a reduction in the capital-output ratio.

Keywords: Economic Growth. Latin America. International Trade. 



\section{Contents}

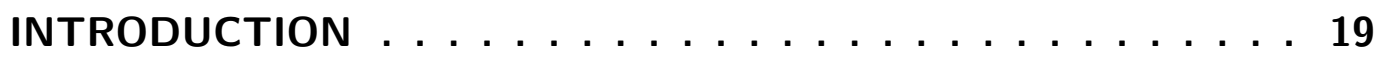

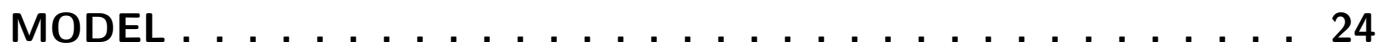

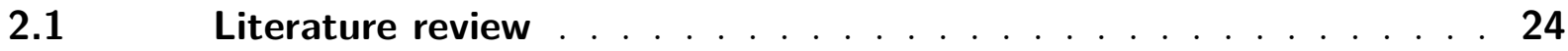

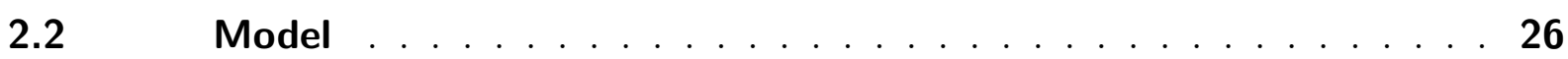

$2.2 .1 \quad$ Closed economy . . . . . . . . . . . . . . . . . . . 27

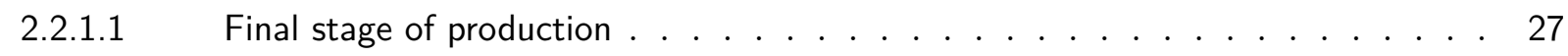

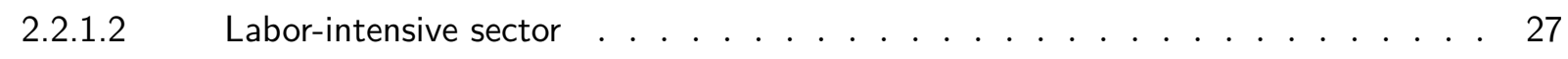

2.2.1.3 Capital-intensive sector . . . . . . . . . . . . . . . . . . 28

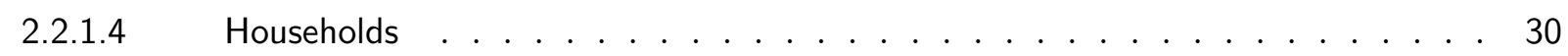

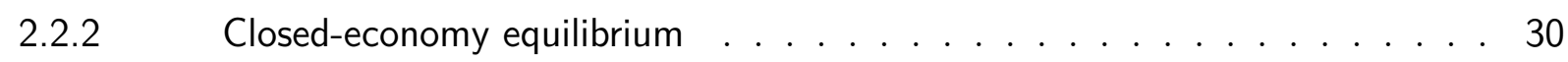

$2.2 .3 \quad$ Closed-economy steady state . . . . . . . . . . . . . . . 31

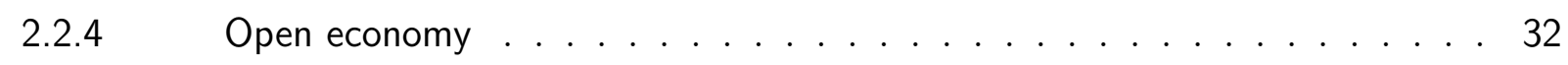

$2.2 .5 \quad$ Reopening the economies . . . . . . . . . . . . . . . . . . 34

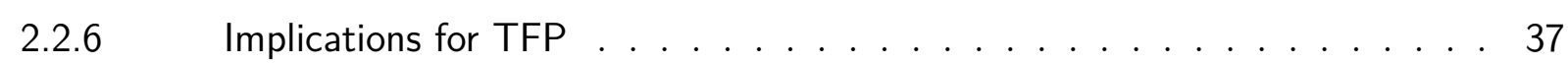

$2.2 .7 \quad$ Transition paths $\ldots \ldots \ldots \ldots \ldots \ldots \ldots$

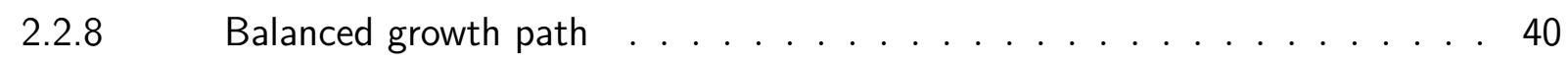

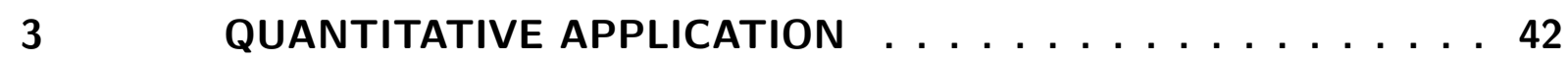

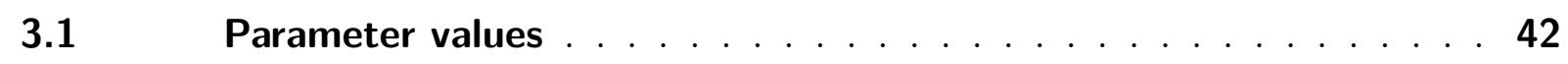

$3.2 \quad$ Impact of the reforms $\ldots \ldots \ldots \ldots \ldots \ldots$

$4 \quad$ CONCLUSION $\ldots \ldots \ldots \ldots \ldots \ldots$

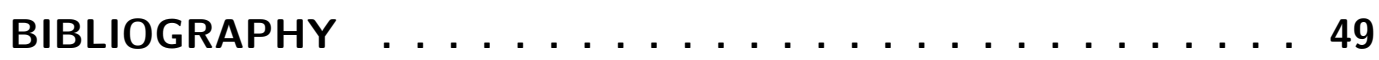

APPENDIX 53

APPENDIX A-EQUATIONS . . . . . . . . . . . 54

A.1 Closed-economy steady state $\ldots \ldots \ldots \ldots \ldots \ldots$

A.2 Open-economy steady state $\ldots \ldots \ldots \ldots \ldots$

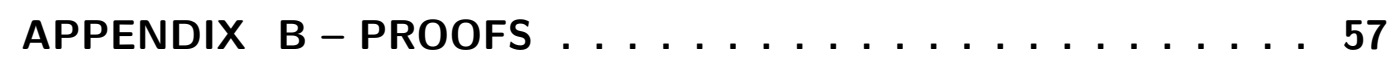

APPENDIX C - COMPUTATION OF TRANSITION PATHS . . 62

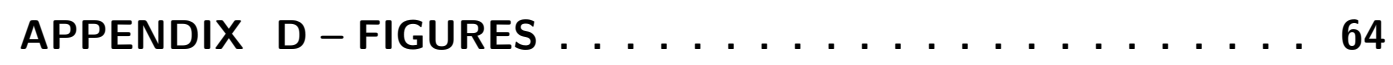





\section{List of Figures}

Figure 1 - Latin America's average import tariff on all products (\%) between 1989

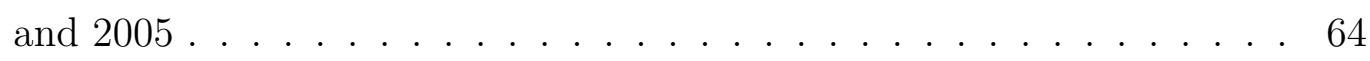

Figure 2 - Latin America's trade share (\% of GDP) between 1960 and 2005 . . . 65

Figure 3 - Trade share (\% of GDP) in $1985 \ldots \ldots$. . . . . . . . . 65

Figure 4 - Trade share $(\%$ of GDP) in $2005 \ldots \ldots$. . . . . . . . . 66

Figure 5 - Average real GDP per capita growth rates of small and large countries in Latin America . . . . . . . . . . . . . . . . . . . . 66

Figure 6 - Total factor productivity of Latin America between 1980 and 2010 . . 67

Figure 7 - Quantity of varieties produced in the closed-economy steady state as a function of $\mathrm{N} \ldots \ldots \ldots$. . . . . . . . . . . . . 6 67

Figure 8 - Capital per capita in the closed-economy steady state as a function of N 68

Figure 9 - Output per capita in the closed-economy steady state as a function of N 68

Figure 10 - Consumption per capita in the closed-economy steady state as a function of $\mathrm{N} \ldots \ldots \ldots \ldots \ldots \ldots$

Figure 11 - Latin America's capital-output ratio between 1985 and 2000 . . . . . . 69

Figure 12 - Transition paths of TFP $(\alpha=0.3$ and $N=0.05) \ldots \ldots$

Figure 13 - Transition paths of TFP $(\alpha=0.99$ and $N=0.05) \ldots \ldots . \ldots$

Figure 14 - Transition paths of capital per capita in the closed economy . . . . . . 71

Figure 15 - Transition paths of output per capita in the closed economy . . . . . . 71

Figure 16 - Transition paths of consumption per capita in the closed economy . . . 72

Figure 17 - Transition paths of capital per capita in the open economy . . . . . . . 72

Figure 18 - Transition paths of output per capita in the open economy . . . . . . . 73

Figure 19 - Transition paths of consumption per capita in the open economy . . . . 73

Figure 20 - Transition paths of $k_{t} / k_{0}$ in the open economy . . . . . . . . . . 74

Figure 21 - Transition paths of $y_{t} / y_{0}$ in the open economy . . . . . . . . . . . . 74

Figure 22 - Transition paths of $c_{t} / c_{0}$ in the open economy . . . . . . . . . . 75

Figure 23 - Transition paths of $y_{t} / y_{0}(\mathrm{~N}=0.01) \ldots \ldots \ldots \ldots$

Figure 24 - Transition paths of $y_{t} / y_{0}(\mathrm{~N}=0.05) \ldots \ldots \ldots \ldots$

Figure 25 - Transition paths of $y_{t} / y_{0}(N=0.20) \ldots \ldots \ldots \ldots$

Figure 26 - GDP per worker (millions of dollars) of Honduras between 1985 and 201777 



\section{List of Tables}

Table 1 - Average real GDP per capita growth rates . . . . . . . . . . . . 21

Table 2 - Average growth rates of Latin America between 1991 and 2000 . . . . 45

Table 3 - Growth rates produced by the model $(\gamma=0,97) \ldots \ldots$. . . . . . . 45

Table 4 - Growth rates produced by the model $(\gamma=0,96) \ldots \ldots$. . . . . . 46 



\section{Introduction}

After the debt crisis of 1982, the majority of Latin American countries realized that a development strategy based on import substitution causes serious macroeconomic problems. For instance, the external sectors of these countries were the most distorted among developing countries, with Central American countries with the highest degree of import protection and South American countries following closely behind (EDWARDS, 1995).

In the late 1980s and early 1990s, countries in this region began a series of economic reforms to adopt pro-market and pro-trade policies (SACHS; WARNER, 1995; FILHO; CHAMON, 2012). These reforms aimed to increase economic growth and diminish the gap between those and industrialized countries. Besides, these reforms created a great enthusiasm for the future economic performance of the region. For example, GDP growth rate projections of more than $6 \%$ per year were common at that time.

Of the economic reforms undertaken by Latin American countries, Loayza and Palacios (1997) claim that the most successful one was trade liberalization. According to them, the reform in this area was the deepest and most generalized in the region. As Edwards (1995) explains, this reform was characterized by four elements:

- Reduction of the coverage of nontariff barriers.

- Reduction of the average level of import tariffs.

- Reduction in the dispersion of the tariff structure.

- Reduction or elimination of export taxes.

In Figure 1, we present Latin America's average tariff on all imported products between 1989 and 2005. As we can observe, the reforms had a significant effect on the reduction in import tariffs, with these tariffs reducing from an average value of $31.92 \%$ in 1989 to an average value of $10.62 \%$ in 2005 . Another important variable to analyze the reforms in Latin America is trade share. In Figure 2, we present Latin America's trade share between 1960 and 2005. It is possible to notice that the reforms were related to a significant increase in this variable, increasing from a value of $28.64 \%$ in 1985 to a value of $46.75 \%$ in 2005. However, Latin America's trade share is a GDP-weighted average of the trade shares of all Latin American countries, not representing the change in each country individually. Thus, in Figures 3 and 4, we present the trade share in 1985 and 2005 of each country in the region. In these figures, we observe an almost uniform movement of 
countries towards a greater trade openness. Therefore, the growth in Latin America's trade share was due to an increase in the trade share of almost every country in the region and not only in a few of them.

According to Edwards (1995), with the reforms, the policymakers in the region wanted to reverse the problems arising from protectionism and to transform international trade into an engine of economic growth, as was observed with the Asian Tigers. There is a large body of literature that indicates that trade openness is essential for growth. For instance, Grossman and Helpman (1993) state that trade openness affects the speed with which small countries can absorb technological innovations developed in industrialized countries. Hsieh, Klenow and Nath (2019) claim that trade liberalization is important for growth because it quickens the pace of creative destruction, thereby speeding the flow of technology. Finally, Perla, Tonetti and Waugh (2021) argue that trade liberalization changes firms' incentives to adopt better technology, and this induces more rapid technology adoption. According to the authors, since the frequency at which firms upgrade their technology is tied to aggregate growth, more open economies grow faster.

However, in Table 1, it is possible to observe that despite the economic recovery in the 1990s in comparison to the 1980s, the economic reforms adopted by Latin American countries did not obtain the desired result, and the average growth rate of the region's GDP per capita in the 1990s was lower than the average growth rates in the 1960s and 1970s, years in which the region was more closed to trade. In addition, there is a certain pattern in the growth of Latin American countries, as we can observe in Figure 5. The largest countries in the region, like Brazil, Mexico and Colombia, had better performances in the 1960s and 1970s, when they were closed to trade, while their performances were significantly worse in the 1990s. On the other hand, for smaller countries, like Bolivia, Chile and Uruguay, their performances were worse in the 1960s and 1970s, while the growth rates of these countries significantly increased in comparison to the other countries in the region in the 1990s.

In addition to output, another important variable for the analysis of the economic growth of Latin America is total factor productivity (TFP). As Easterly and Levine (2001) and Loayza, Fajnzylber and Calderón (2005) point out, international evidence indicates that changes in a country's growth are mainly due to changes in the behavior of TFP, with the accumulation of factors of production having only a secondary role. This primary role of TFP's growth can be seen during the recovery of Latin American economies in the 1990s. Loayza, Fajnzylber and Calderón (2005) claim that in $80 \%$ of the countries in this region, the economic recovery in the 1990s was due to an increase in TFP. In Figure 6, we show Latin America's TFP between 1980 and 2010. In this figure, it is possible to observe a great reduction in the TFP of the region during the 1980s and, after that, a significant increase in this variable. 
Table 1 - Average real GDP per capita growth rates

\begin{tabular}{|c|c|c|c|c|}
\cline { 2 - 5 } \multicolumn{1}{c|}{} & $1961-1970$ & $1971-1980$ & $1981-1990$ & $1991-2000$ \\
\hline Argentina & $2.15 \%$ & $0.93 \%$ & $-2.60 \%$ & $2.93 \%$ \\
\hline Bolivia & $0.17 \%$ & $1.68 \%$ & $-1.87 \%$ & $1.75 \%$ \\
\hline Brazil & $4.40 \%$ & $6.05 \%$ & $-0.52 \%$ & $0.86 \%$ \\
\hline Chile & $2.05 \%$ & $0.87 \%$ & $1.27 \%$ & $4.89 \%$ \\
\hline Colombia & $2.15 \%$ & $3.12 \%$ & $1.24 \%$ & $0.97 \%$ \\
\hline Costa Rica & $2.67 \%$ & $2.96 \%$ & $-0,20 \%$ & $2.38 \%$ \\
\hline Dominican Republic & $2.38 \%$ & $4.43 \%$ & $0.26 \%$ & $4.20 \%$ \\
\hline Ecuador & $1.42 \%$ & $4.02 \%$ & $0.09 \%$ & $-0.11 \%$ \\
\hline El Salvador & $1.98 \%$ & $0.96 \%$ & $-1.37 \%$ & $3.46 \%$ \\
\hline Guatemala & $2.90 \%$ & $2.95 \%$ & $-1.52 \%$ & $1.75 \%$ \\
\hline Haiti & $-1.25 \%$ & $2.78 \%$ & $-2.66 \%$ & $-1.84 \%$ \\
\hline Honduras & $0.40 \%$ & $2.25 \%$ & $-0.58 \%$ & $0.48 \%$ \\
\hline Jamaica & $2.68 \%$ & $-2.16 \%$ & $1.29 \%$ & $0.52 \%$ \\
\hline Mexico & $3.35 \%$ & $3.56 \%$ & $-0.28 \%$ & $1.79 \%$ \\
\hline Panama & $6.24 \%$ & $2.75 \%$ & $0.16 \%$ & $2.94 \%$ \\
\hline Paraguay & $1,69 \%$ & $5,80 \%$ & $0,23 \%$ & $-0.49 \%$ \\
\hline Peru & $2.34 \%$ & $0.98 \%$ & $-3.25 \%$ & $2.14 \%$ \\
\hline Trinidad and Tobago & $3.61 \%$ & $3.83 \%$ & $-3.53 \%$ & $4.04 \%$ \\
\hline Uruguay & $0.30 \%$ & $2.64 \%$ & $-0.18 \%$ & $2.44 \%$ \\
\hline Venezuela & $3.11 \%$ & $1.24 \%$ & $-1.94 \%$ & $-0.03 \%$ \\
\hline Latin America (20) & $3.05 \%$ & $3.62 \%$ & $-0.71 \%$ & $1.44 \%$ \\
\hline
\end{tabular}

Notes: Data from PWT 9.1 (Feenstra, Inklaar and Timmer (2015)) and author's calculations. GDP per capita is PPP adjusted. These countries represent the twenty greatest economies in Latin America in 1990.

In this paper, we introduce a dynamic general equilibrium model for a better understanding of the relationship between international trade and economic growth. The framework of the model is similar to that observed in Rodrigues (2010), a dynamic Heckscher-Ohlin model with scale economies in the capital-intensive sector. However, while Rodrigues (2010) analyzes the impact of trade restrictions, considering as motivation the adoption of import substitution policies in Latin America in the 1960s and 1970s, we analyze the effects of a trade liberalization, considering as motivation the economic reforms in the same region during the 1990s.

Our paper is related to a series of papers that explore dynamic Heckscher-Ohlin models, such as Chen (1992), Ventura (1997), Atkeson and Kehoe (2000), Bond, Trask and Wang (2003) and Ferreira and Trejos (2006). We assume an economy composed of two countries, two basic factors (capital and labor) and two sectors. In both countries, economic agents are equal. That is, firms produce with the same technologies and households have the same preferences. However, unlike usual dynamic Heckscher-Ohlin models in which firms operate constant returns to scale technologies, in our model, we introduce scale economies in the capital-intensive sector. 
As Rodrigues (2010) states, the production framework of the model is similar to those found in Ethier (1982) and Helpman and Krugman (1985). While the labor-intensive sector is composed of competitive firms using a constant returns to scale technology, the capital-intensive sector is composed of differentiated variety producers that behave as monopolistic competitors. This structure is interesting since it allows for factor price equalization even in the absence of competitive markets. Furthermore, since economies of scale appear through an increase in the quantity of varieties available, the model has characteristics similar to those observed in Grossman and Helpman (1991) and Rivera-Batiz and Romer (1991). In these papers, output growth is associated with the introduction of new goods.

The addition of scale economies to the capital-intensive sector is responsible for the main mechanism of our model. After both countries reopen their economies, the world capital stock is always smaller than the world capital stock of the open-economy steady state. Therefore, both countries accumulate capital after the reopening, but it is possible to observe a difference between these processes of accumulation. While the larger country is a net exporter of varieties and accumulates more capital relative to its output, the smaller country exports the labor-intensive good and accumulates less capital relative to its output. This difference in the accumulation of capital relative to output and the economic growth caused by the reopening of the economies are responsible for the main results of the paper.

Our model has results similar to Latin America's experience during the 1990s. Firstly, the model can qualitatively replicate what occurred in the region during the reforms in the 1990s. When countries similar in size to an average Latin American country reopen their economies, we can observe an increase in output and TFP and, also, a reduction in the capital-output ratio. Secondly, the difference in performance between large and small countries can also be reproduced by our model. As in Latin America, in our model, large countries grow faster when they are closed to trade, while small countries grow faster when they are open to trade. Finally, the model produces growth rates very close to those observed for an average Latin American country for output per worker, TFP and the capital-output ratio. Therefore, considering the similarity between the results obtained by our model and Latin America's experience in the 1990s, we consider that a dynamic Heckscher-Ohlin model with scale economies in the capital-intensive sector can account for some of the main characteristics of Latin America's growth not only in the years in which the region adopted import substitution policies, as was observed by Rodrigues (2010), but also during the economic reforms in the 1990s.

The paper is organized as follows. In the next chapter, we present a review of the literature about dynamic Heckscher-Ohlin models, and we introduce our model and its main results. In the third chapter, we present the quantitative results of the model, when it 
is calibrated to replicate the economic environment of an average Latin American country during the 1990s. Finally, in the fourth chapter, we conclude the paper. 


\section{Model}

\subsection{Literature review}

The literature related to dynamic Heckscher-Ohlin models begins with Oniki and Uzawa (1965). As the authors write, the paper aims to formulate a dynamic model of international trade, considering an economy with two countries, two factors of production and two sectors. Moreover, the authors present the result that the pattern of trade is determined by differences in factor endowments between the two countries. However, unlike later models, they assume an exogenous and constant savings rate for each country.

Improving the previous model, Chen (1992) dismisses the assumption of an exogenous savings rate and makes the choices of this variable and consumption endogenous. The author demonstrates that there is an infinite number of possible steady-state equilibria in an open economy with diversified production. Another interesting result, which also occurs in our model, is the presence of a hysteresis effect. This effect implies that the country with a larger initial stock of capital per capita will have a larger stock of capital per capita in the open-economy steady state when we consider identical and homothetic preferences with constant intertemporal elasticity of substitution.

Ventura (1997) claims that the two most interesting facts about the international growth in the post-war period are the conditional convergence and the economic miracle of East Asian countries. Trying to create a model that can explain these two situations, he formulates a dynamic Heckscher-Ohlin model considering utility-maximizing consumers with identical preferences. Imposing assumptions to guarantee that a conditional version of factor price equalization is always valid, the author obtains the result that if countries diversify their production throughout their path, the elasticity of substitution between traded goods is essential to determine the behavior of convergence. Besides, the author also states that in international trade models in which factor price equalization is valid, the law of diminishing returns applies only to world averages. Thus, in a given period, investment is equally productive in each country, so differences in growth rates can only be attributed to differences in investment rates.

Considering a usual dynamic Heckscher-Ohlin model, Atkeson and Kehoe (2000) study the behavior of economies that are equal in every aspect, except for the moment when they start their development, that is, the moment when they enter their optimal path. The authors work with a small open economy and consider that the rest of the world is already in steady state. The main result of this paper is that late-bloomers with an initial capital-labor ratio below the diversification cone end up with a level of income per 
capita permanently lower than early-bloomers.

Some papers study the results that can be obtained after weakening some of the assumptions generally used in dynamic Heckscher-Ohlin models. For example, Bond, Iwasa and Nishimura (2009) do not assume homothetic preferences. The authors demonstrate that if there are no labor productivity differences and the discount rates are equal across countries, the Heckscher-Ohlin theorem will still be valid. However, if there are labor productivity differences or the discount rates are different, the Heckscher-Ohlin theorem could be violated. Another interesting paper and also by the same previous authors is Bond, Iwasa and Nishimura (2013). In this paper, the authors present the results that can be obtained when the labor-intensive good is inferior. In this situation, it is possible to observe multiple steady states in a closed economy, which can generate a situation of a "poverty trap" for countries that have a small initial capital stock.

$\mathrm{Hu}$, Kemp and Shimomura (2009) argue that most of the literature on growth and international trade focuses mainly on technological innovation. However, to understand the relationship between growth and international trade in a developing country, the authors state that it is essential to study the accumulation of both physical and human capital. In the paper, they explain that the introduction of adjustment costs in the accumulation of human capital negatively affects the long-run growth rate. Moreover, in a two-country world, the difference between the countries in the formation of human capital opens the way to balanced growth.

Also studying the effects of international trade on output, Ferreira and Trejos (2006) develop a dynamic Heckscher-Ohlin model focusing on the case of a price-taking open economy. In this model, it is possible to observe that tariffs and other trade barriers are negatively correlated with TFP. Furthermore, poor countries with protectionist policies will have lower levels of capital and output, and they may not converge to the level of income of developed countries in the long run because there are two asymptotically stable steady states.

Introducing Heckscher-Ohlin trade features into a two-country dynamic stochastic general equilibrium model, Cuñat and Maffezzoli (2004) formulate a model that emphasizes the transmission of cycles through commodity trade and, at the same time, explains why countries trade and their patterns of specialization. In this paper, for instance, the model generates correlations of different signs between terms of trade and countries' income.

Dynamic models of international trade were formulated in different ways over time. One of the early options was to combine Heckscher-Ohlin models with growth models with two sectors and infinitely-lived consumers. On the other hand, other models were developed incorporating the Hecksher-Ohlin framework in an overlapping generations environment. Bajona and Kehoe (2006) introduce a framework that tries to join these two different assumptions. They find that the results of the model significantly depend on the 
assumptions made on international capital markets and on the demographic environment.

Bajona and Kehoe (2010) study the dynamic properties of a dynamic HeckscherOhlin model where international borrowing and lending are not permitted. They obtain two main results. Firstly, even when factor price equalization is valid, countries that differ only in their initial endowments may converge or diverge in terms of output over time, depending on the elasticity of substitution between traded goods. Secondly, factor price equalization in a given period does not imply factor price equalization in future periods.

The main reference for our model, Rodrigues (2010) formulates a dynamic HeckscherOhlin model that can qualitatively account for the peculiar facts that characterized Latin America's economic growth during import substitution years. Unlike usual dynamic Heckscher-Ohlin models, the author incorporates scale economies in the capital-intensive sector. Thus, the size of the economy matters for the values of the main variables in the closed-economy steady state. Moreover, the model is also able to quantitatively reproduce some of the main characteristics of Latin America's growth when it adopted import substitution as a development strategy.

\subsection{Model}

The model to be introduced is based mainly on Rodrigues (2010). Our framework is a dynamic Heckscher-Ohlin model with economies of scale in the capital-intensive sector. The economy in this model is composed of two countries (Home and Foreign), two basic factors (capital and labor) and two sectors. We consider time as discrete, that is, $t=0,1,2, \ldots$, and we do not add uncertainty to the model.

In this model, we intend to reproduce a situation of a trade liberalization with small growth, considering as motivation the reforms undertaken by Latin American countries in the 1990s. In the model, both countries are in the closed-economy steady state before they reopen their economies, which is a situation similar to the experience of Latin American countries that reopened their economies after adopting import substitution policies.

In this section, we begin by introducing the situation in which both countries are closed to trade. This situation is particularly important for us because it represents the initial condition of our model. After that, we introduce the main part of our model, we allow international trade, and we obtain some analytical results in this situation. These results are especially important because they demonstrate how the model can qualitatively account for some of the characteristics of Latin America's growth in the 1990s. Moreover, we also simulate some transition paths to observe the model's response to two trade policies, and, additionally, we introduce to the model the possibility of long-run growth. 


\subsubsection{Closed economy}

First of all, we describe firms and households in Home (firms and households in Foreign are exactly equal). In addition, we present the market clearing conditions for the closed economy and some results that we can obtain in this situation.

\subsubsection{Final stage of production}

We begin with the final stage of production. We assume that it is composed of a competitive firm, the good that it produces is the numeraire of the economy, and the firm operates the following production function:

$$
Y_{t}=Y_{1 t}^{\omega} Y_{2 t}^{1-\omega}
$$

where $Y_{1 t}$ is the quantity of good 1 at period $t$ (produced by the labor-intensive sector), $Y_{2 t}$ is the quantity of good 2 at period $t$ (produced by the capital-intensive sector) and $\omega$ $\in(0,1)$.

The firm in this sector solves the following problem:

$$
\text { Max. } Y_{t}-p_{1 t} Y_{1 t}-p_{2 t} Y_{2 t} \text { subject to } Y_{t}=Y_{1 t}^{\omega} Y_{2 t}^{1-\omega}
$$

where $p_{1 t}$ is the price of good 1 at period $t$ and $p_{2 t}$ is the price of good 2 at period $t$.

Solving the problem above, we obtain the following equation:

$$
\frac{p_{1 t}}{p_{2 t}}=\frac{\omega}{1-\omega} \frac{Y_{2 t}}{Y_{1 t}}
$$

Besides, considering the cost minimization problem, it is possible to obtain:

$$
1=\frac{p_{1 t}^{\omega}}{\omega^{\omega}} \frac{p_{2 t}^{1-\omega}}{(1-\omega)^{1-\omega}}
$$

\subsubsection{Labor-intensive sector}

The labor-intensive sector (sector 1) is similar to the final stage of production. We assume that it is a competitive market, and firms operate a Cobb-Douglas technology with capital and labor as inputs:

$$
Y_{1 t}=K_{1 t}^{\theta_{1}} L_{1 t}^{1-\theta_{1}}
$$


where $K_{1 t}$ and $L_{1 t}$ are the quantities of capital and labor used in sector 1 at period $t$, respectively, and $\theta_{1} \in(0,1)$.

The problem of firms in this sector is:

Max. $p_{1 t} Y_{1 t}-w_{t} L_{1 t}-r_{t} K_{1 t}$ subject to $Y_{1 t}=K_{1 t}^{\theta_{1}} L_{1 t}^{1-\theta_{1}}$,

where $w_{t}$ is the wage and $r_{t}$ is the rental rate of capital, both at period $t$. Solving the problem, we have that:

$$
\begin{gathered}
p_{1 t} \theta_{1} k_{1 t}^{\theta_{1}-1}=r_{t} \\
p_{1 t}\left(1-\theta_{1}\right) k_{1 t}^{\theta_{1}}=w_{t},
\end{gathered}
$$

where $k_{1 t}$ is the capital-labor ratio of sector 1 at period $t$.

Also, from the cost minimization problem:

$$
p_{1 t}=\frac{w_{t}^{1-\theta_{1}}}{\theta_{1}^{\theta_{1}}} \frac{r_{t}^{\theta_{1}}}{\left(1-\theta_{1}\right)^{1-\theta_{1}}}
$$

\subsubsection{Capital-intensive sector}

We model the production structure of the capital-intensive sector (sector 2) as a two-stage process. In the second stage, we assume that a competitive firm uses the varieties produced in the first stage as inputs. The firm has the following production function:

$$
Y_{2 t}=\left(\int_{0}^{n_{t}} x_{i t}^{\gamma} d i\right)^{\frac{1}{\gamma}}
$$

where $x_{i t}$ is the quantity of variety $i$ at period $t, n_{t}$ is the quantity of varieties produced at period $t$ and $\gamma \in(0,1)$.

In this case, the firm solves the following problem:

$$
\text { Max. } p_{2 t} Y_{2 t}-\int_{0}^{n_{t}} p_{i t} x_{i t} d_{i} \text { subject to } Y_{2 t}=\left(\int_{0}^{n_{t}} x_{i t}^{\gamma} d i\right)^{\frac{1}{\gamma}}
$$

where $p_{i t}$ is the price of variety $i$ at period $t$.

Solving the problem, we obtain the following demand for each variety: 


$$
x_{i t}=\left(\frac{p_{i t}}{p_{2 t}}\right)^{\frac{1}{\gamma-1}} Y_{2 t}
$$

Also, given that there are no profits in this stage, we have that:

$$
p_{2 t}=\left(\int_{0}^{n_{t}} p_{i t}^{\frac{-\gamma}{1-\gamma}} d i\right)^{\frac{-(1-\gamma)}{\gamma}}
$$

In the first stage, we assume that firms behave as monopolistic competitors, with each firm producing a variety $i$, where $i \in\left[0, n_{t}\right]$, and they use capital and labor as inputs. Variety i's producer operates the following production function:

$$
x_{i t}=K_{i 2 t}^{\theta_{2}} L_{i 2 t}^{1-\theta_{2}}-f,
$$

where $K_{i 2 t}$ and $L_{i 2 t}$ are the quantities of capital and labor used in the production of variety $i$ at period $t$, respectively, and $\theta_{2} \in(0,1)$. We also assume that $\theta_{2}>\theta_{1}$ and $f$ is a fixed cost to produce.

Variety i's producer solves the following problem:

Max. $p_{i t} x_{i t}-\psi_{t}\left(x_{i t}+f\right)$ subject to $x_{i t}=\left(\frac{p_{i t}}{p_{2 t}}\right)^{\frac{1}{\gamma-1}} Y_{2 t}$ and $\psi_{t}=\frac{r_{t}^{\theta_{2}}}{\theta_{2}^{\theta_{2}}} \frac{w_{t}^{1-\theta_{2}}}{\left(1-\theta_{2}\right)^{1-\theta_{2}}}$,

where $\psi_{t}$ is the marginal cost of the variety producer ${ }^{1}$.

Solving the problem above, we obtain the following result:

$$
p_{i t}=\frac{1}{\gamma} \frac{r_{t}^{\theta_{2}}}{\theta_{2}^{\theta_{2}}} \frac{w_{t}^{1-\theta_{2}}}{\left(1-\theta_{2}\right)^{1-\theta_{2}}}
$$

Moreover, due to free entry, we have a zero profit condition given by:

$$
p_{i t} x_{i t}=\psi_{t}\left(x_{i t}+f\right)
$$

Since $f$ is the same for every firm, we have that:

$$
x_{i t}=x=\frac{\gamma}{1-\gamma} f
$$

that is, production is constant across time and varieties. According to Rodrigues (2010), this means that changes in sector 2 occur through changes in the number of varieties produced, but not through changes in output per variety.

1 Note that if we solve the cost minimization problem, we obtain the following Cost function: $T C\left(x_{i t}\right)=$ $\frac{r_{t}^{\theta_{2}}}{\theta_{2}^{\theta_{2}}} \frac{w_{t}^{1-\theta_{2}}}{\left(1-\theta_{2}\right)^{\left(1-\theta_{2}\right)}}\left(x_{i t}+f\right)$ 
In the first stage, we can also obtain the following equality:

$$
\frac{\theta_{2}}{\left(1-\theta_{2}\right)} \frac{L_{i 2 t}}{K_{i 2 t}}=\frac{r_{t}}{w_{t}}
$$

Due to symmetry, all firms use the same quantities of capital and labor in equilibrium. Thus, $K_{i 2 t}=K_{2 t}$ and $L_{i 2 t}=L_{2 t}$. Moreover, the capital-labor ratio of each variety at period $t$ is denoted by $k_{2 t}$. That is, $k_{2 t}=K_{2 t} / L_{2 t}$

\subsubsection{Households}

In the model, we assume that there is a continuum of infinitely-lived households with measure N. Each household is endowed with one unit of time in every period, which is supplied inelastically, and they have the same quantity of capital at the initial period $(t=0)$. Moreover, the income received can be used either for consumption or investment, and we assume log utility:

$$
u\left(c_{t}\right)=\log \left(c_{t}\right)
$$

From the assumptions above, each household solves the following problem:

Max. $\sum_{t=0}^{+\infty} \beta^{t} \log \left(c_{t}\right)$ subject to $c_{t}+k_{t+1}-(1-\delta) k_{t} \leq w_{t}+r_{t} k_{t}, \forall t=0,1, \ldots$,

where $c_{t}$ is consumption per capita at period $t, k_{t}$ is capital per capita at period $t$ and $\delta$ is the depreciation rate of capital (constant through all periods). From the problem above, it is possible to obtain the following Euler equation:

$$
c_{t+1}=\beta c_{t}\left(r_{t+1}+(1-\delta)\right)
$$

\subsubsection{Closed-economy equilibrium}

To complete the model, it is necessary to impose the market clearing conditions for factors and the final good. Hence, we have that:

$$
\begin{gathered}
L_{1 t}+n_{t} L_{2 t}=N \\
K_{1 t}+n_{t} K_{2 t}=N k_{t} \\
N\left(c_{t}+k_{t+1}-(1-\delta) k_{t}\right)=Y_{t},
\end{gathered}
$$


these equations together with equations (2.1), (2.4), (2.7) and (2.10) are the equilibrium conditions in domestic markets for the closed economy.

Thus, we can define the equilibrium of the closed economy as a sequence of price and allocations $\left\{p_{t}, p_{1 t}, p_{2 t}, w_{t}, r_{t}, K_{1 t}, K_{2 t}, L_{1 t}, L_{2 t}, n_{t}, x, c_{t}, k_{t+1}\right\}_{t=0}^{+\infty}$ that satisfies equations (2.1)-(2.18) for a given initial level of capital per capita $k_{0}$.

\subsubsection{Closed-economy steady state}

In this section, we analyze the closed-economy steady state. As in Rodrigues (2010), in the closed-economy steady state, variables generally depend on the size of the economy $(\mathrm{N})$. The next assumption is to ensure that in the closed-economy steady state, $n(N)$ (variables in the steady state of a closed economy of size $\mathrm{N}$ are denoted this way or without the time subscript when the size of the economy is clear), $c(N), k(N)$ and $y(N)$ are increasing functions of $\mathrm{N}$.

Assumption 1: $\gamma>\frac{(1-\omega) \theta 2}{\left(1-\omega \theta_{1}\right)}$

Assumption 1 allows us to obtain Proposition 1, which is also presented in Rodrigues (2010):

Proposition 1: Given Assumption 1, in the closed-economy steady state, $n(N), c(N)$, $k(N)$ and $y(N)$ are increasing functions of $\mathrm{N}$.

Proof: Proposition 1 of Rodrigues (2010).

According to Rodrigues (2010), we have that:

$$
\begin{gathered}
n(N)=T_{n} N^{\frac{\gamma\left[\omega\left(1-\theta_{1}\right)+(1-\omega)\left(1-\theta_{2}\right)\right]}{\gamma\left(1-\omega \theta_{1}\right)-(1-\omega) \theta_{2}}} \\
k(N)=T_{k} N^{\frac{(1-\gamma)(1-\omega)}{\gamma\left(1-\omega \theta_{1}\right)-(1-\omega) \theta_{2}}} \\
y(N)=T_{y} N^{\frac{(1-\gamma)(1-\omega)}{\gamma\left(1-\omega \theta_{1}\right)-(1-\omega) \theta_{2}}} \\
c(N)=T_{c} N^{\frac{(1-\gamma)(1-\omega)}{\gamma\left(1-\omega \theta_{1}\right)-(1-\omega) \theta_{2}}}
\end{gathered}
$$

where $T_{n}, T_{k}, T_{y}$ and $T_{c}$ are constants. Therefore, as we can notice in the equations above, 
the main variables are affected by the size of the economy in the closed-economy steady state. In Figures 7, 8, 9 and 10, we present the graphs of these variables as functions of N.

For the next results in the paper, we also use the following corollary:

Corollary 1: In the closed-economy steady state, $w(N)$ is an increasing function of $\mathrm{N}$.

Proof: Appendix B

\subsubsection{Open economy}

In this section, we introduce in the model a second country called Foreign. All its variables are denoted with an asterisk. Except for this notation, its size and its initial capital per capita, this country is exactly equal to Home. Also, following Rodrigues (2010), we normalize the size of the world economy to 1 . That is, $N+N^{*}=1$.

With the introduction of the new country, the countries are allowed to trade good 1 and varieties costlessly. This possibility changes the market clearing conditions for tradable goods and good 2 :

$$
\begin{gathered}
Y_{1 t}+Y_{1 t}^{*}=K_{1 t}^{\theta_{1}} L_{1 t}^{\left(1-\theta_{1}\right)}+K_{1 t}^{* \theta_{1}} L_{1 t}^{*\left(1-\theta_{1}\right)} \\
Y_{2 t}=\left(n_{t}+n_{t}^{*}\right)^{\frac{1}{\gamma}} x_{t}^{d} \\
Y_{2 t}^{*}=\left(n_{t}+n_{t}^{*}\right)^{\frac{1}{\gamma}} x_{t}^{* d} \\
x=x_{t}^{d}+x_{t}^{* d}
\end{gathered}
$$

where $Y_{1 t}\left(Y_{1 t}^{*}\right)$ is the demand for good 1 by Home (Foreign) at period $t, x_{t}^{d}\left(x_{t}^{* d}\right)$ is the demand for each variety by Home (Foreign) at period $t$ and $Y_{2 t}\left(Y_{2 t}^{*}\right)$ is the quantity of good 2 produced by Home (Foreign) at period $t$.

We also assume that trade is balanced in all periods. In other words, we have the following conditions in every period:

$$
\begin{gathered}
p_{1 t} Y_{1 t}+p_{t}\left(n_{t}+n_{t}^{*}\right) x_{t}^{d}=p_{1 t} K_{1 t}^{\theta_{1}} L_{1 t}^{\left(1-\theta_{1}\right)}+p_{t} n_{t} x \\
p_{1 t} Y_{1 t}^{*}+p_{t}\left(n_{t}+n_{t}^{*}\right) x_{t}^{* d}=p_{1 t} K_{1 t}^{* \theta_{1}} L_{1 t}^{*\left(1-\theta_{1}\right)}+p_{t} n_{t}^{*} x
\end{gathered}
$$


The description of the open-economy equilibrium is given by the equations introduced in this section, the optimal decision of each economic agent and the market clearing conditions for factors and goods that are not internationally traded. It is worth mentioning that some equations appear twice. Since they are similar to those of the closed economy, we have one equation for Home and another for Foreign.

A well-known theorem in the international trade literature is the Factor Price Equalization theorem (SAMUELSON, 1948). This result states that when countries are within the cone of diversification, they have the same factor prices. Rodrigues (2010) shows that in the open-economy steady state both countries are within the cone of diversification (variables in the open-economy steady state are denoted with the open subscript). This result is presented in Proposition 2:

Proposition 2: In the open-economy steady state, $r_{\text {open }}, w_{\text {open }}, p_{2 o p e n}, k_{1 o p e n}, k_{2 o p e n}$, $K_{2 o p e n}$ and $L_{2 o p e n}$ are equalized across countries.

Proof: Proposition 2 of Rodrigues (2010).

It is also possible to prove that prices and capital-labor ratios assume values in the open-economy steady state equal to their respective values in the steady state of a closed economy of size 1 . This is because when all countries are inside the cone of diversification, the production techniques used are equivalent to those of an integrated economy, in which there is free mobility of factors of production. However, in the case of an open economy, this free mobility of factors is replaced by the possibility of trade between countries. Proposition 3 presents this result:

Proposition 3: In the open-economy steady state, $r_{\text {open }}, w_{\text {open }}, k_{1 \text { open }}, k_{2 o p e n}, K_{2 o p e n}$ and $L_{2 o p e n}$ coincide with their respective steady-state values in a closed economy of size 1.

Proof: Proposition 3 of Rodrigues (2010)

The result above allows us to determine world quantities of each variable. On the other hand, it is not possible to determine the quantity of each variable for each country because there are several ways to allocate the world capital between the two countries (considering that both of them are within the cone of diversification). However, if the initial capital per capita stocks of Home $\left(k_{0}\right)$ and Foreign $\left(k_{0}^{*}\right)$ are determined, the steady-state equilibrium is unique. 


\subsubsection{Reopening the economies}

In this section, we assume that both countries are in their closed-economy steady state when trade restrictions are unexpectedly lifted at period 1. Moreover, we assume that the countries are in the cone of diversification in all periods after the reopening.

Assumption 2: Both countries are in the cone of diversification $\forall t=1,2, \ldots$

Before the first result in this section, note that considering the intertemporal budget constraint and the Euler equation (2.15), we can obtain the following demand for consumption at period $t$ :

$$
c_{t}=(1-\beta)\left(\sum_{i=t+1}^{+\infty}\left(\prod_{j=t+1}^{i} \frac{1}{r_{j}+1-\delta}\right) w_{i}+w_{t}+\left(1+r_{t}-\delta\right) k_{t}\right)
$$

Therefore, at period 1, we have that:

$$
c_{1}=(1-\beta)\left(\sum_{i=2}^{+\infty}\left(\prod_{j=2}^{i} \frac{1}{r_{j}+1-\delta}\right) w_{i}+w_{1}+\left(1+r_{t}-\delta\right) k(N)\right)
$$

Given Assumption 2 and considering equation (2.30), it is possible to obtain Proposition 4:

Proposition 4: Given Assumption 2 and assuming that $N \neq N^{*}$, in the open-economy steady state, the larger country has greater consumption per capita, capital per capita and output per capita in comparison to the smaller country.

Proof: Appendix B

This result is similar to the one obtained by Chen (1992). This result is called the hysteresis effect. According to Bond, Iwasa and Nishimura (2013), the hysteresis effect implies that the country with a larger initial stock of capital per capita in a two-country trade model will have a larger stock of capital per capita in the open-economy steady state.

A direct corollary is obtained from the proposition above:

Corollary 2: If $N=N^{*}=1 / 2$, the countries have the same consumption per capita, capital per capita and output per capita in the open-economy steady state. In addition, $k_{\text {open }}^{*}=k_{\text {open }}=k(1)$. 
In the case of the corollary above, note that we have a situation of a symmetric equilibrium, so the countries make the same decisions. Thus, both countries only trade varieties. In other words, we only have intra-industry trade.

In Table 1, we can note that the 1990s was a period of economic recovery compared to the 1980s. In our model, the reopening of the economies to trade has a similar effect on output, capital and consumption per capita. That is, these variables in the open-economy steady state are greater than in the closed-economy steady state. We can see this result in the next proposition:

Proposition 5: Given Assumption 2, for every $N \in(0,1), k_{\text {open }}>k(N), k_{\text {open }}^{*}>k^{*}\left(N^{*}\right)$, $c_{\text {open }}>c(N), c_{\text {open }}^{*}>c^{*}\left(N^{*}\right), y_{\text {open }}>y(N)$ and $y_{\text {open }}^{*}>y^{*}\left(N^{*}\right)$.

\section{Proof: Appendix B}

Proposition 5 presents how the model can qualitatively account for some of the main characteristics of Latin America's growth in the 1990s. This is because, after the reopening of the economies to trade, we can observe an increase in the output of each country, similar to Latin America's economic recovery in the 1990s. Therefore, Proposition 5 ensures that the model can qualitatively replicate the economic recovery observed in Latin America in the 1990s.

Additionally, we can observe that both countries benefit from the possibility of international trade. It is possible to notice that capital, consumption and output per capita are greater in the open-economy steady state in comparison to the closed-economy steady state. For output, this result is supported by the empirical literature, as we can observe in Frankel and Romer (1999), Frankel and Rose (2002), Alesina, Spolaore and Wacziarg (2005), Chang, Kaltani and Loayza (2009) and Estevadeordal and Taylor (2013).

Another interesting point is that unlike the hysteresis effect observed by Chen (1992), in which a country with a lower capital per capita stock ended up in a worse situation in the open-economy steady state in comparison to the closed-economy steady state in output terms. In our model, regardless of a country's initial stock of capital per capita, its situation in the open-economy steady state is better than in the closed-economy steady state. This is because both countries accumulate capital after the reopening. From what we have observed, the result in our model is more consistent with the empirical literature and with what occurred in Latin America during the 1990s.

An important variable for the study of Latin America between the 1960s and the 1980s, due to the adoption of import substitution policies by Latin American countries, the capital-output ratio of the region presented a significant increase during this period. Hopenhayn and Neumeyer (2004) note that between 1960 and 1985 this variable grew 
at values almost equal to the values observed in East Asian countries, an average value of $1.39 \%$ per year. However, with the economic reforms in the 1990s, especially trade liberalization, countries in Latin America reduced their import protection, and this caused a reduction in their capital-output ratio. In Figure 11, we show Latin America's capitaloutput ratio between 1985 and 2000. As we can see in the figure, the strong increase in the 1960s, 1970s and 1980s, which was noted by Hopenhayn and Neumeyer (2004) and Rodrigues (2010), no longer occur in the 1990s. Instead, during the 1990s, the region presents a small reduction in this variable. In the following proposition, we can observe that the model is able to qualitatively replicate this reduction:

Proposition 6: 1) If $\mathrm{N}=1 / 2, k_{\text {open }} / y_{\text {open }}=k(N) / y(N)$ and $c(N) / y(N)=c_{\text {open }} / y_{\text {open }}$.

2) If $N \in(0,1 / 2), k_{\text {open }} / y_{\text {open }}<k(N) / y(N)$ and $c(N) / y(N)<c_{\text {open }} / y_{\text {open }}$.

3) If $N \in(1 / 2,1), k_{\text {open }} / y_{\text {open }}>k(N) / y(N)$ and $c(N) / y(N)>c_{\text {open }} / y_{\text {open }}$.

Proof: Appendix B

From the results above, the smaller country presents a reduction in its capitaloutput ratio. This is because this country increases production in the labor-intensive sector, thereby not requiring a high accumulation of capital. Since an average Latin American country is always smaller than its trade partner, our model can qualitatively replicate what happened in the region with regard to the capital-output ratio during the 1990s.

Moreover, Proposition 6 is similar to Proposition 4 and Corollary 1 of Rodrigues (2010). However, while in Rodrigues (2010) trade restrictions cause an increase in the capital-output ratio of a country regardless of its size, in our model, the behavior of the capital-output ratio of a country after the trade liberalization depends on its size.

From Proposition 6, we can observe that:

- If $N \in(0,1 / 2), c_{o p e n} / c(N)>y_{\text {open }} / y(N)>k_{\text {open }} / k(N)$.

- If $N \in(1 / 2,1), c_{\text {open }} / c(N)<y_{\text {open }} / y(N)<k_{\text {open }} / k(N)$.

- If $N=1 / 2, c_{\text {open }} / c(N)=y_{\text {open }} / y(N)=k_{\text {open }} / k(N)$.

It is interesting to note that the functions $k(),. y($.$) and c($.$) (obtained in Proposition$ 1) are continuous and strictly increasing functions of the size of the economy (N). It is also noted that these functions can assume the value 0 and do not have an upper bound. Thus, by the intermediate value theorem, we know that $\exists N_{y}, N_{c}, N_{k} \in[0,+\infty)$ such that $y\left(N_{y}\right)=y_{\text {open }}, c\left(N_{c}\right)=c_{\text {open }}$ and $k\left(N_{k}\right)=k_{\text {open }}$. Furthermore, because the previous functions are strictly increasing in $\mathrm{N}$ (due to Assumption 1), we have that $N_{y}, N_{c}$ and $N_{k}$ are unique. Therefore, we have that: 
- If $N \in(0,1 / 2), 1>N_{c}>N_{y}>N_{k}>N$

- If $N \in(1 / 2,1), N_{k}>N_{y}>N_{c}>1>N$

- If $N=1 / 2,1=N_{k}=N_{y}=N_{c}>N$

Additionally, it is interesting to compare the relative growth in capital, consumption and output between the two countries. In the following proposition, we present these comparisons:

Proposition 7: 1) If $N \in(0,1 / 2), c_{\text {open }} / c(N)>c_{\text {open }}^{*} / c^{*}\left(N^{*}\right), y_{\text {open }} / y(N)>y_{\text {open }}^{*} / y^{*}\left(N^{*}\right)$ and $k_{\text {open }} / k(N)>k_{\text {open }}^{*} / k^{*}\left(N^{*}\right)$.

2) If $N \in(1 / 2,1), c_{\text {open }} / c(N)<c_{\text {open }}^{*} / c^{*}\left(N^{*}\right), y_{\text {open }} / y(N)<y_{\text {open }}^{*} / y^{*}\left(N^{*}\right)$ and $k_{\text {open }} / k(N)<$ $k_{\text {open }}^{*} / k^{*}\left(N^{*}\right)$.

3) If $N=1 / 2, c_{\text {open }} / c(N)=c_{\text {open }}^{*} / c^{*}\left(N^{*}\right), y_{\text {open }} / y(N)=y_{\text {open }}^{*} / y^{*}\left(N^{*}\right)$ and $k_{\text {open }} / k(N)=$ $k_{\text {open }}^{*} / k^{*}\left(N^{*}\right)$.

Proof: Appendix B

Proposition 7 indicates that the smaller country presents greater relative growth in output, consumption and capital per capita in comparison to the larger country after they reopen their economies. For output, this result is consistent with Alesina, Spolaore and Wacziarg (2000), Alesina, Spolaore and Wacziarg (2005) and Spolaore and Wacziarg (2005) that present empirical evidence that small countries benefit more from trade than large countries, mainly due to the scale effect.

\subsubsection{Implications for TFP}

In this section, we study the effects of the trade liberalization on total factor productivity (TFP). Firstly, we assume that TFP is measured using a Cobb-Douglas production function for the aggregate economy:

$$
Y_{t}=A_{t} K_{t}^{\alpha} N_{t}^{1-\alpha}
$$

where $A_{t}$ is TFP at period $t$ and $\alpha \in(0,1)$.

From the previous equation and results, it is possible to observe that for countries with $N \in(0,1 / 2]$, TFP increases in the long run as result of the trade liberalization. This result is presented in the following proposition:

Proposition 8: If $N \in(0,1 / 2], A_{\text {open }}>A(N)$. 
Proof: Appendix B

Proposition 8 is consistent with the empirical literature, as we can observe in Coe and Helpman (1995), Coe, Helpman and Hoffmaister (1997), Edwards (1998) and Blyde and Fernández-Arias (2004). In Figure 13, we show the behavior of the TFPs of Home and Foreign when $\alpha=0.3$ and $N=0.05$.

Furthermore, since an average Latin American country is always smaller than its trade partner, Proposition 8 ensures that the model is able to qualitatively replicate the increase in Latin America's TFP in the 1990s, which we can observe in Figure 6.

For the case $N \in(1 / 2,1)$, the behavior of TFP depends on the values of the parameters. We can observe that TFP can increase or decrease depending on the value of $\alpha$. For extreme cases:

- If $\alpha=0, A(N)=\frac{T_{y}}{T_{k}^{\alpha}} N^{\frac{(1-\omega)(1-\gamma)}{\gamma\left(1-\omega \theta_{1}\right)-\theta_{2}(1-\omega)}}<\frac{T_{y}}{T_{k}^{\alpha}} N_{y}^{\frac{(1-\omega)(1-\gamma)}{\gamma\left(1-\omega \theta_{1}\right)-\theta_{2}(1-\omega)}}=A_{o p e n}$.

- If $\alpha=1, A(N)=\frac{T_{y}}{T_{k}^{\alpha}}>\frac{T_{y}}{T_{k}^{\alpha}}\left(\frac{N_{y}}{N_{k}}\right)^{\frac{(1-\omega)(1-\gamma)}{\gamma\left(1-\omega \theta_{1}\right)-\theta_{2}(1-\omega)}}=A_{\text {open }}$.

Thus, from the results above, using the intermediate value theorem, we know that $\exists \alpha^{*} \in(0,1)$ such that $A(N)=A_{\text {open }}$. In Figure 13, we show the behavior of the TFPs of Home and Foreign when $\alpha=0.99$. In this figure, it is possible to observe a reduction in the TFP of Foreign.

Following Proposition 7, it is interesting to compare the relative growth in TFP between the two countries:

Proposition 9: 1) If $N \in(0,1 / 2), A_{\text {open }} / A(N)>A_{\text {open }}^{*} / A^{*}\left(N^{*}\right)$.

2) If $\mathrm{N}=1 / 2, A_{\text {open }} / A(N)=A_{\text {open }}^{*} / A^{*}\left(N^{*}\right)$.

3) If $N \in(1 / 2,1), A_{\text {open }} / A(N)<A_{\text {open }}^{*} / A^{*}\left(N^{*}\right)$.

Proof: Appendix B

Therefore, the reopening of the economies makes the TFP of the smaller country grow relatively more, as can be seen in Figure 12. TFP is governed mainly by the number of varieties available in a country. Since the quantity of varieties available in the closedeconomy steady state $(n(N))$ is an increasing function of $\mathrm{N}$, the smaller country has a smaller quantity of varieties available in the closed-economy steady state. With the reopening of the economies and after they reach the open-economy steady state, the quantity of varieties available is the same for both countries, corresponding to the quantity produced in the closed-economy steady state of a country of size 1 . This means that the 
smaller country presents a higher increase in the number of varieties available. Therefore, the smaller country exhibits a greater relative increase in TFP.

\subsubsection{Transition paths}

In this section, we observe the model's response to two trade policies. We simulate the transition paths for three countries with different sizes: $N=0.01, N=0.05$ and $N=0.20$. In the first case, as in Rodrigues (2010), we consider that the countries implement restrictions that fully prohibit trade. Moreover, we consider that the initial condition of these countries is the lower limit of the cone of diversification. In the second case, after these countries reach the closed-economy steady state, we consider that the trade restrictions are removed, and these countries reopen their economies to trade.

In Figures 14, 15 and 16, we present the transition paths of capital, consumption and output per capita for the three countries after the restrictions to trade. As we can observe in Figure 14, after the implementation of the trade restrictions, all countries show an increase in their capital per capita. It is worth noting the result of Proposition 1, the larger country accumulates more capital when the economy closes. In Figures 15 and 16, we can observe the paths of consumption and output for the three countries. There is an increase in output for all countries, but consumption moves to a lower level in comparison to the initial period for the countries with $N=0.05$ and $N=0.01$. It is also worth mentioning that shortly after the implementation of the trade restrictions, we can observe a reduction in consumption and output in every country. As Rodrigues (2010) states, this is because these countries no longer have access to the varieties produced by their trade partners, and it is necessary to produce them internally. However, in order to achieve this, it is necessary to shift resources to sector 2 .

Considering that after the trade restrictions are implemented, the countries reach the closed-economy steady state, we simulate how these countries respond to a reopening. In Figures 17, 18 and 19, we present the transition paths of capital, output and consumption after the countries reopen to trade. It is worth noting that, as noted in Proposition 5, all variables present an increase in comparison to their values in the closed-economy steady state. It is also possible to observe that the largest country presents transition paths superior to the other countries for all variables. However, in the case of a reopening to trade, the countries leave from different initial conditions, so it is not interesting to compare the paths of the variables without making an adjustment.

To adjust the problem presented in the previous paragraph, in Figures 20, 21 and 22 , we present the transition paths of the variables normalized by their initial conditions. In other words, considering $z_{t}$ as the variable of interest, we present the path of $z_{t} / z_{0}$. For capital, as in the previous case, the largest country presents a transition path superior to the other countries. However, for output and consumption, we have that the smallest 
country presents transition paths superior to the other countries, which is a result consistent with Alesina, Spolaore and Wacziarg (2005). This result can be mainly explained by the increase in wages and in the quantity of varieties available when the countries are open to trade.

As noted in the introduction, Latin America's growth during the reforms in the 1990s was smaller than under the protectionist policies in the 1960s and 1970s. Hence, in the next simulations, we compare the path of output growth when the country is closed to when the country is open to trade. These comparisons for the different countries are shown in Figures 23, 24 and 25. It is observed that for two of the three countries, the average growth rate in the long run when the economy is closed is higher than when the economy is open to trade, which is similar to Latin America's experience during the reforms in the 1990s (Table 1). However, for $\mathrm{N}=0.01$, the output growth when the economy is open is greater than when it is closed to trade. As it was discussed in the introduction, these results are similar to the performances of some Latin American countries. For instance, in the model, large countries have a higher economic growth when they are closed in comparison to when they are open to trade. Similarly, in Latin America, large countries like Brazil, Mexico and Colombia presented a higher economic growth during the time they were adopting import substitution policies than during the reforms in the 1990s. On the other hand, for small countries, the growth of output when they are open to trade is greater than when they are closed, as in the case of Bolivia, Chile and Uruguay, which grew more in the 1990s than in the 1960s and 1970s when we compare them to the other countries in the region.

\subsubsection{Balanced growth path}

In this section, we allow countries to have a constant growth rate in the long run. Following Rodrigues (2010), the possibility of long-run growth is included by allowing country sizes to grow at a constant rate $g(N)$. That is, $N_{t}=N_{0}(1+g(N))^{t}$ and $N_{t}^{*}=$ $N_{0}^{*}(1+g(N))^{t}$. Furthermore, we also assume that the sum of $N_{0}$ and $N_{0}^{*}$ is equal to 1 .

From the discussion in the previous paragraph, it is easily observed that the longrun growth rate of the size of the world economy is also constant and equal to $g(N)$. In other words, we have that $g\left(N_{w}\right)=g(N)$, where the variables with a subscript $w$ correspond to the values that variables assume for the world economy. Considering this result, it is possible to obtain Proposition 10:

Proposition 10: If the world economy is in a balanced growth path and the growth rate of the size of the world economy is $g(N)$, then $g\left(k_{w}\right)=g\left(y_{w}\right)=g\left(c_{w}\right)$ and:

$$
g\left(k_{w}\right)=\frac{(1-\gamma)(1-\omega) g(N)}{\gamma\left(1-\omega \theta_{1}\right)-(1-\omega) \theta_{2}}
$$


Proof: Proposition 5 of Rodrigues (2010)

Because of Assumption 1, the world economy presents a positive and constant growth rate in the long run.

Although obtaining the long-run growth rate of the world economy is interesting, we want to focus on the individual economic performance of each country. Therefore, the main interest rests in the long-run growth rate of these countries. Thus, from the proposition above, we can obtain the following corollary:

Corollary 5: If the world economy and both countries are in a balanced growth path and the growth rate of country sizes is equal to $g(N)$, then $g\left(k_{w}\right)=g(k)=g\left(k^{*}\right)=$ $g(y)=g\left(y^{*}\right)=g(c)=g\left(c^{*}\right)$ and:

$$
g\left(k_{w}\right)=\frac{(1-\gamma)(1-\omega) g(N)}{\gamma\left(1-\omega \theta_{1}\right)-(1-\omega) \theta_{2}}
$$

Proof: Appendix B

From the corollary above, we can observe that in a balanced growth path, capital, consumption and output have the same growth rate for both countries and the world economy.

Considering the results obtained previously, it is also possible to notice that the growth rate of TFP for both countries and the world economy in a balanced growth path is equal to the one obtained by Rodrigues (2010):

$$
g\left(A_{w}\right)=g(A)=g\left(A^{*}\right)=(1-\alpha) g\left(k_{w}\right)
$$




\section{Quantitative Application}

In this section, we observe our model's performance when we calibrate it to replicate the economic environment of an average Latin American country in the 1990s. The results are compared to the data observed in Latin America between 1991 and 2000. In the first part of this section, we describe how the parameter values were chosen, and in the second part, we discuss the results produced by the model.

\subsection{Parameter values}

The values of capital shares $\left(\theta_{1}\right.$ and $\left.\theta_{2}\right)$ and the share of the labor-intensive good $(\omega)$ are the same used by Cuñat and Maffezzoli (2004) and Rodrigues (2010). Hence, we have that $\theta_{1}=0.17, \theta_{2}=0.49$ and $\omega=0.61$. Furthermore, following Rodrigues (2010), $\alpha=0.3$.

In the simulations, we measure the size of the country by its stock of efficiency units of labor, that is, $N=E L$, where $L$ is the number of workers and $E$ is an index efficiency, which we consider as an exogenous TFP. During all simulations, we assume that factor price equalization is valid. In fact, this assumption has empirical support. For example, Trefler (1993) obtains the result that there is evidence of factor price equalization after we consider productivity differences among countries.

Considering that $N=E L$, the aggregate production function can be written as $Y_{t}=A_{t} K_{t}^{\alpha}\left(E_{t} L_{t}\right)^{1-\alpha}$. Thus, TFP can be expressed as:

$$
T F P_{t}=A_{t} E_{t}^{1-\alpha}
$$

where we consider $E_{t}$ as the exogenous part of TFP and $A_{t}$ as the endogenous part.

In the balanced growth path section, we assumed that $N$ grew at a constant rate $g(N)$. For the simulations in the next section, since $N=E L$, we assume that $L$ is constant, but $E$ has a constant growth rate $g(E)$. Therefore, we have the following growth rates in a balanced growth path:

$$
\begin{gathered}
g\left(\frac{Y}{L}\right)=\left(1+\frac{(1-\gamma)(1-\omega)}{\gamma\left(1-\omega \theta_{1}\right)-(1-\omega) \theta_{2}}\right) g(E) \\
g(A)=\frac{(1-\alpha)(1-\gamma)(1-\omega)}{\gamma\left(1-\omega \theta_{1}\right)-(1-\omega) \theta_{2}} g(E)
\end{gathered}
$$


Observing that the scale of the countries are measured by efficiency units of labor, we follow Rodrigues (2010) and set $E / E^{*}=0.31$. For the values of $N$ and $N^{*}$, we also follow the same strategy of Rodrigues (2010). In the first case, we consider that Foreign is the greatest trade partner of Latin America in 1990, that is, the USA. Comparing the number of workers of an average Latin American country to the number of workers of the USA, we have that $L / L^{*} \approx 6.7 \%$. Thus, this implies $N \approx 0.02$.

Furthermore, we also consider a second case in which Foreign corresponds to the three greatest trade partners of Latin America in 1990, that is, the USA, Japan and Germany. After comparing the number of workers of an average Latin American country to the number of workers of these three countries in 1990 , we obtain that $N \approx 0.01$. In addition, we also report the results for $N=0.05, N=0.10$ and $N=0.20$ to observe the performance of economies that have greater size.

We calibrate $\gamma$ and $g(E)$ to match in a balanced growth path the average GDP per worker growth rate of the $\mathrm{G} 7^{1}$ between 1980 and 2010, which was $1.80 \%$ per year. Moreover, we choose values of $\gamma$ and $g(E)$ that ensure that the ratio of the output per worker of Home to the output per worker of Foreign in the closed-economy steady state is equal to the ratio of the GDP per worker of an average Latin American country to the GDP per worker of the USA in 1990, which was approximately $28.49 \%$. Thus, we set $\gamma=0.97$ and $g(E)=0.0177$.

Finally, as in Rodrigues (2010), we set $f=0.10, \beta=0.96$ and $\delta=0.10$.

\subsection{Impact of the reforms}

In the simulations, we are interested in the growth rates of output per worker, TFP and capital-output ratio produced by our model. Nevertheless, differently from the previous simulations, in which countries completely reopened to trade, we also perform simulations in which countries partially reopen to trade. In these simulations, we calibrate the model to match two values of Latin America's average trade share in 2000: $67.14 \%$ (average trade share at current national prices) and, considering only merchandise trade, $50.69 \%$ (average merchandise trade as a share of GDP at current PPPs) ${ }^{2}$. To implement this partial reopening, the size of the world economy will no longer be 1 . Instead, it will be determined by the value of the trade share of Home, which will be equal to one of the two values above.

Additionally, for the calculation of the growth rates, we use two equations. Firstly, for the growth rate of output per worker, we use:

1 The United States, Japan, Germany, the United Kingdom, France, Italy and Canada.

2 Data from PWT 9.1 (Feenstra, Inklaar and Timmer (2015)) for the two values of trade share. 


$$
\hat{Y / L}=\left(\frac{\tilde{y_{10}}}{\tilde{y_{0}}}\right)^{\frac{1}{10}}\left(1+g\left(\frac{Y}{L}\right)\right)-1
$$

where $\tilde{y}$ represents the detrended output per worker. Additionally, for the growth rate of TFP, we use the following equation:

$$
T \hat{F} P=(1-\alpha) \hat{Y / L}-\alpha \hat{K / Y}
$$

where $\hat{K / Y}$ is the capital-output ratio's growth rate.

In Table 2, we present the average growth rates of GDP per worker, TFP and capital-output ratio of Latin America between 1991 and 2000. However, since some countries in the region were suffering from political conflicts and institutional instability, we decided to work with a second group of Latin American countries. In this second group, we take out the seven countries with the worst performance in the "Political Instability and Absence of Violence/Terrorism" index ${ }^{3}$ in 2000. These seven countries are Colombia, Ecuador, Guatemala, Haiti, Paraguay, Peru and Venezuela. These countries were chosen because the country with the best performance in the index in 2000 among these countries was Ecuador. As Cueva and Diaz (2018) observe, Ecuador entered into a war against Peru in the middle 1990s, suffered from a high political instability, Barracca (2007) states that the country suffered from a coup attempt in 2000, and was seriously affected by the severe El Niño event of 1997-1998. Considering all these events, we believe that their occurrence had a great effect on Ecuador's economy, and our model is not capable of capturing them. Moreover, these seven countries are the ones which consistently appear among the countries with the worst performance in the index in the other years for which we have data in the period of interest, 1996 and 1998.

Besides, we also take out Honduras from the second group. This decision is because this country presents the lowest average growth rate of GDP per worker among the countries in the region in the period that we are studying and because we believe that this catastrophic performance is due to the initial period chosen (1990). In Figure 26, we present the GDP per worker of Honduras between 1985 and 2017. In this figure, we can observe that the GDP per worker of Honduras reaches its highest value in $1990^{4}$ and its variation in the period was very high (its growth rate from 1989 to 1990 was superior to $15 \%$ and from 1990 to 1991 was inferior to $-22 \%$ ). Therefore, due to the high variation and the low performance of the GDP per worker of Honduras, we decided to take Honduras out of the second group. Taking out these eight countries, every country in the second group had a positive average growth rate of GDP per worker during the period we are studying,

3 Data from the Worldwide Governance Indicators

4 The second-highest value of the GDP per worker of Honduras in the data available on PWT 9.1. 
which we believe is a good indicator for the method chosen. Thus, the performance of the model will be compared to the data of the second group of countries.

Table 2 - Average growth rates of Latin America between 1991 and 2000

\begin{tabular}{|l|c|c|c|}
\cline { 2 - 4 } \multicolumn{1}{c|}{} & GDP per worker $(Y / L)$ & Capital-output ratio $(K / Y)$ & Total factor productivity $(T F P)$ \\
\hline Latin America (20) & $0.62 \%$ & $0.02 \%$ & $0.43 \%$ \\
\hline Latin America (12) & $1.89 \%$ & $-0.41 \%$ & $1.44 \%$ \\
\hline
\end{tabular}

Notes: Data from PWT 9.1 (Feenstra, Inklaar and Timmer (2015)) and author's calculations. For each group, numbers represent average growth rates across all countries in the group. GDP per worker is PPP adjusted.

Table 3 displays the average growth rates produced by the model for output per worker, capital-output ratio and TFP. In the first and second sets of columns, we impose Home to exhibit a trade share of $50.69 \%$ and $67.14 \%$, respectively. In the third set of columns, we present the results when we impose Home to produce an average growth rate of output per worker similar to the one observed in Latin America. In this case, since we already know the average growth rate of output per worker, we report the trade share that corresponds to this particular growth rate. Finally, in the fourth set of columns, we simulate a situation where Home completely reopens to international trade. That is, we consider the size of the world economy equal to 1 .

In Table 3, it is possible to notice, as expected, that in every simulation, the model can qualitatively replicate what happened in Latin America. In other words, Home presents an increase in output per worker and TFP and a decrease in the capital-output ratio. For sizes of Home equivalent to those of an average Latin American country, $N=0.01$ or $N=0.02$, we can observe that the values are close to the data in the three first columns, especially for output per worker and TFP. In the last column, as expected, the model produces growth rates with absolute values greater than what was observed in the data.

Table 3 - Growth rates produced by the model $(\gamma=0,97)$

\begin{tabular}{|c|c|c|c|c|c|c|c|c|c|c|c|c|}
\hline & \multicolumn{3}{|c|}{$T R_{\text {Home }}=50.69 \%$} & \multicolumn{3}{|c|}{$T R_{\text {Home }}=67.14 \%$} & \multicolumn{3}{|c|}{ Exact } & \multicolumn{3}{|c|}{ Full open } \\
\hline & $Y / L$ & $K / Y$ & $T F P$ & $Y / L$ & $K / Y$ & $T F P$ & $T R_{\text {Home }}$ & $K / Y$ & $T F P$ & $Y / L$ & $K / Y$ & $T F P$ \\
\hline$N=0.01$ & $1.85 \%$ & $-0.30 \%$ & $1.38 \%$ & $1.95 \%$ & $-0.43 \%$ & $1.49 \%$ & $60.74 \%$ & $-0.37 \%$ & $1.44 \%$ & $2.38 \%$ & $-0.56 \%$ & $1.83 \%$ \\
\hline$N=0.02$ & $1.86 \%$ & $-0.26 \%$ & $1.38 \%$ & $1.97 \%$ & $-0.37 \%$ & $1.49 \%$ & $57.80 \%$ & $-0.30 \%$ & $1.42 \%$ & $2.29 \%$ & $-0.47 \%$ & $1.75 \%$ \\
\hline$N=0.05$ & $1.89 \%$ & $-0.20 \%$ & $1.38 \%$ & $2.01 \%$ & $-0.29 \%$ & $1.49 \%$ & $50.69 \%$ & $-0.20 \%$ & $1.38 \%$ & $2.18 \%$ & $-0.35 \%$ & $1.63 \%$ \\
\hline$N=0.10$ & $1.91 \%$ & $-0.16 \%$ & $1.38 \%$ & $2.04 \%$ & $-0.23 \%$ & $1.50 \%$ & $46.91 \%$ & $-0.15 \%$ & $1.37 \%$ & $2.10 \%$ & $-0.25 \%$ & $1.56 \%$ \\
\hline$N=0.20$ & $1.93 \%$ & $-0.11 \%$ & $1.39 \%$ & - & - & - & $39.91 \%$ & $-0.15 \%$ & $1.35 \%$ & $2.02 \%$ & $-0.15 \%$ & $1.46 \%$ \\
\hline
\end{tabular}

Notes: In the first set of columns, we present the results of the model when we calibrate it to exhibit a trade share of Home equal to $50.69 \%$. In the second set of columns, we present the results of the model when we calibrate it to exhibit a trade share of Home equal to $67.14 \%$. In the third set of columns, we present the results of the model when we calibrate it to produce a growth rate of output per worker of $1.89 \%$. Moreover, instead of presenting the growth rate of output per worker in the first of the columns in this set, we report the trade share of Home. In the fourth set of columns, we present the results predicted by the model when Home fully reopens to trade. Finally, the cells without any values are due to the fact that countries with $N=0.20$ cannot reach a trade share of $67.14 \%$.

Since this paper can be considered an extension of Rodrigues (2010), we report in Table 4 the results of the model when $\gamma=0.96$, which is the same value used by Rodrigues 
(2010) and it is similar to the value used in the simulations in Table 3. Moreover, to keep the same growth rate of output per worker in a balanced growth path, we set $g(E)=0.0176$.

In Table 4, it is possible to observe again that the model can qualitatively replicate what happened in Latin America. For $N=0.01$ and $N=0.02$, the values predicted by the model are closer to the data, especially for the capital-output ratio and TFP. In our preferred specification, $N=0.01$ and $T R_{\text {Home }}=50.69 \%$, the values are particularly close to the data. The model produces a growth rate of output per worker of $1.85 \%$, a growth rate of the capital-output ratio of $-0.40 \%$ and a growth rate of TFP of $1.42 \%$, whereas, in the data, we observe a growth rate of GDP per worker of $1.89 \%$, a growth rate of the capital-output ratio of $-0.41 \%$ and a growth rate of TFP of $1.44 \%$.

Table 4 - Growth rates produced by the model $(\gamma=0,96)$

\begin{tabular}{|c|c|c|c|c|c|c|c|c|c|c|c|c|}
\hline & \multicolumn{3}{|c|}{$T R_{\text {Home }}=50.69 \%$} & \multicolumn{3}{|c|}{$T R_{\text {Home }}=67.14 \%$} & \multicolumn{3}{|c|}{ Exact } & \multicolumn{3}{|c|}{ Full open } \\
\hline & $Y / L$ & $K / Y$ & $T F P$ & $Y / L$ & $K / Y$ & $T F P$ & $T R_{H}$ & $K / Y$ & $T F P$ & $Y / L$ & $K / Y$ & $T F P$ \\
\hline No & $1.85 \%$ & $.40 \%$ & $1.42 \%$ & $1.99 \%$ & $-0.57 \%$ & $1.57 \%$ & $57.13 \%$ & $-0.47 \%$ & $.46 \%$ & $2.60 \%$ & $-0.76 \%$ & $.04 \%$ \\
\hline$N=$ & $88 \%$ & 0.35 & $1.42 \%$ & $2.03 \%$ & $-0.50 \%$ & $1.57 \%$ & 51. & $-0.36 \%$ & 1.4 & $2.47 \%$ & $-0.64 \%$ & $1.92 \%$ \\
\hline & $92 \%$ & $0.27 \%$ & 1.4 & $2.08 \%$ & -0 & 1.5 & & $-0.24 \%$ & & $2.32 \%$ & $-0.47 \%$ & $1.76 \%$ \\
\hline & $5 \%$ & $22 \%$ & 1.4 & $12 \%$ & 0.31 & 1.58 & & $-0.17 \%$ & 10 & $2.21 \%$ & $-0.34 \%$ & $1.65 \%$ \\
\hline$N=0.20$ & $1.98 \%$ & $-0.15 \%$ & $1.43 \%$ & & - & - & $34.64 \%$ & $-0.17 \%$ & $1.35 \%$ & $2.10 \%$ & $-0.20 \%$ & $1.53 \%$ \\
\hline
\end{tabular}

Notes: In the first set of columns, we present the results of the model when we calibrate it to exhibit a trade share of Home equal to $50.69 \%$. In the second set of columns, we present the results of the model when we calibrate it to exhibit a trade share of Home equal to $67.14 \%$. In the third set of columns, we present the results of the model when we calibrate it to produce a growth rate of output per worker of $1.89 \%$. Moreover, instead of presenting the growth rate of output per worker in the first of the columns in this set, we report the trade share of Home. In the fourth set of columns, we present the results predicted by the model when Home fully reopens to trade. Finally, the cells without any values are due to the fact that countries with $N=0.20$ cannot reach a trade share of $67.14 \%$. 


\section{Conclusion}

One of the most famous books on Latin American economies in the 1990s, Edwards (1995) claims that the reforms implemented in Latin America were impressive. Countries implemented major stabilization programs, opened their markets to international trade and privatized a large number of state-owned companies. These policies generated great enthusiasm for the region's growth, analysts projected growth rates above $6 \%$ per year, and some of them even claimed that some Latin American countries were on their way to become a new generation of Tigers. However, despite an economic recovery compared to the 1980s, the expectation of high growth did not materialize in the 1990s, and the region's economic performance was worse than in the 1960s and 1970s, frustrating the high expectations regarding the region.

In this paper, we developed a dynamic general equilibrium model that was based on Rodrigues (2010). The model is constructed in a way that is similar to the situation of Latin American countries during the reforms in the 1990s, that is, a transition from a closed economy to a more open economy. We replicate this situation considering the closed-economy steady state as the initial condition and, after that, reopening the countries to trade. As we observed, the model was able to reproduce some of the main characteristics observed in Latin America's economic growth in the 1990s. The main mechanism behind these results is the accumulation of capital after the reopening, which is possible due to the introduction of scale economies.

In our model, countries with sizes similar to the size of an average Latin American country are able to qualitatively replicate what happened in the region for variables like output, TFP and capital-output ratio. In Proposition 5, it is possible to observe that output always increases after a reopening, similar to Latin America's economic recovery in the 1990s. Similarly, the reduction in the capital-output ratio and the increase in TFP are also observed in Propositions 6 and 8, respectively.

In addition to the analytical results, we also performed simulations to check if the model would be able to quantitatively reproduce the growth rates observed for an average Latin American country in the 1990s. As was presented in the previous section, in our preferred specification, $N=0.01$ and $T R_{H o m e}=50.69 \%$, the values produced by our model are particularly close to the data.

Finally, considering the model's ability to reproduce, both qualitatively and quantitatively, some of the main characteristics of the economic growth of the region during the 1990s, we conclude that a dynamic Heckscher-Ohlin model with scale economies in the capital-intensive sector can account for some of the main characteristics of Latin America's 
growth not only in the years in which the region adopted import substitution policies, as was observed by Rodrigues (2010), but also during the economic reforms in the 1990s. 


\section{Bibliography}

ALESINA, A.; SPOLAORE, E.; WACZIARG, R. Economic integration and political disintegration. American Economic Review, v. 90, n. 5, p. 1276-1296, December 2000.

ALESINA, A.; SPOLAORE, E.; WACZIARG, R. Trade, growth and the size of countries. In: AGHION, P.; DURLAUF, S. (Ed.). Handbook of Economic Growth. 1. ed. [S.l.]: Elsevier, 2005. v. 1, Part B, cap. 23, p. 1499-1542.

ATKESON, A.; KEHOE, P. Research Department Staff Report 256, Paths of development for early- and late-bloomers in a dynamic Heckscher-Ohlin model. 2000.

BAJONA, C.; KEHOE, T. Research Department Staff Report 377, Demographics in dynamic Heckscher-Ohlin models: overlapping generations model versus infinitely lived consumers. 2006.

BAJONA, C.; KEHOE, T. J. Trade, growth, and convergence in a dynamic heckscher-ohlin model. Review of Economic Dynamics, Elsevier BV, v. 13, n. 3, p. 487-513, jul. 2010.

BANK, W. World Development Indicators 2016. [S.l.]: The World Bank, 2016.

BARRACCA, S. Military Coups in the Post-Cold War Era: Pakistan, Ecuador and Venezuela. Third World Quarterly, [Taylor Francis, Ltd., Third World Quarterly], v. 28, n. 1, p. 137-154, 2007. ISSN 01436597, 13602241.

BLYDE, J.; FERNáNDEZ-ARIAS, E. Why does Latin America Grow More Slowly? 04 2004.

BOND, E.; IWASA, K.; NISHIMURA, K. A Dynamic Two Country Heckscher-Ohlin Model with Non-Homothetic Preferences. [S.l.], 2009.

BOND, E. W.; IWASA, K.; NISHIMURA, K. Poverty traps and inferior goods in a dynamic heckscher-ohlin model. Macroeconomic Dynamics, Cambridge University Press, v. 17 , n. 6 , p. 1227-1251, 2013.

BOND, E. W.; TRASK, K.; WANG, P. Factor accumulation and trade: Dynamic comparative advantage with endogenous physical and human capital. International Economic Review, [Economics Department of the University of Pennsylvania, Wiley, Institute of Social and Economic Research, Osaka University], v. 44, n. 3, p. 1041-1060, 2003. ISSN 00206598, 14682354.

CHANG, R.; KALTANI, L.; LOAYZA, N. V. Openness can be good for growth: The role of policy complementarities. Journal of Development Economics, Elsevier BV, v. 90, n. 1, p. 33-49, set. 2009.

CHEN, Z. Long-run equilibria in a dynamic heckscher-ohlin model. The Canadian Journal of Economics / Revue canadienne d'Economique, [Wiley, Canadian Economics Association], v. 25, n. 4, p. 923-943, 1992. ISSN 00084085, 15405982.

COE, D. T.; HELPMAN, E. International r\&d spillovers. European Economic Review, Elsevier BV, v. 39, n. 5, p. 859-887, maio 1995. 
COE, D. T.; HELPMAN, E.; HOFFMAISTER, A. W. North-south r \& d spillovers. The Economic Journal, [Royal Economic Society, Wiley], v. 107, n. 440, p. 134-149, 1997. ISSN 00130133, 14680297.

CUEVA, S.; DIAZ, J. P. The Fiscal and Monetary History of Ecuador: 1950-2015. SSRN Electronic Journal, Elsevier BV, 2018.

CUÑAT, A.; MAFFEZZOLI, M. Heckscher-ohlin business cycles. Review of Economic Dynamics, Elsevier BV, v. 7, n. 3, p. 555-585, jul. 2004.

EASTERLY, W.; LEVINE, R. It's not factor accumulation: Stylized facts and growth models. The World Bank Economic Review, Oxford University Press, v. 15, n. 2, p. 177-219, 2001. ISSN 02586770, 1564698X.

EDWARDS, S. Crisis and Reform in Latin America: From Despair to Hope (A World Bank Publication). [S.1.]: World Bank Publications, 1995. ISBN 0195211057.

EDWARDS, S. Openness, productivity and growth: What do we really know? The Economic Journal, [Royal Economic Society, Wiley], v. 108, n. 447, p. 383-398, 1998. ISSN 00130133, 14680297.

ESTEVADEORDAL, A.; TAYLOR, A. M. Is the Washington Consensus Dead? Growth, Openness, and the Great Liberalization, 1970s-2000s. MIT Press - Journals, v. 95, n. 5, p. 1669-1690, dez. 2013.

ETHIER, W. National and international returns to scale in the modern theory of international trade. American Economic Review, v. 72, n. 3, p. 389-405, 1982.

FEENSTRA, R. C.; INKLAAR, R.; TIMMER, M. P. The Next Generation of the Penn World Table. American Economic Review, v. 105, n. 10, p. 3150-82, October 2015.

FERREIRA, P. C.; TREJOS, A. On the output effects of barriers to trade. International Economic Review, [Economics Department of the University of Pennsylvania, Wiley, Institute of Social and Economic Research, Osaka University], v. 47, n. 4, p. 1319-1340, 2006. ISSN 00206598, 14682354.

FILHO, I. de C.; CHAMON, M. The myth of post-reform income stagnation: Evidence from Brazil and Mexico. Journal of Development Economics, v. 97, n. 2, p. 368-386, 2012.

FRANKEL, J.; ROSE, A. An estimate of the effect of common currencies on trade and income. The Quarterly Journal of Economics, Oxford University Press, v. 117, n. 2, p. 437-466, 2002. ISSN 00335533, 15314650.

FRANKEL, J. A.; ROMER, D. H. Does trade cause growth? American Economic Review, v. 89, n. 3, p. 379-399, June 1999.

GROSSMAN, G.; HELPMAN, E. Trade, knowledge spillovers, and growth. European Economic Review, v. 35, n. 2-3, p. 517-526, 1991.

GROSSMAN, G. M.; HELPMAN, E. Innovation and Growth in the Global Economy. [S.l.]: MIT Press, 1993. ISBN 0262570971.

HELPMAN, E.; KRUGMAN, P. R. Market Structure and Foreign Trade: Increasing Returns, Imperfect Competition, and the International Economy. [S.l.]: Mit Pr, 1985. ISBN 0262081504. 
HOPENHAYN, H. A.; NEUMEYER, P. A. Latin America in the XXth century: stagnation, then collapse. 2004.

HSIEH, C.-T.; KLENOW, P. J.; NATH, I. B. A Global View of Creative Destruction. [S.l.], 2019. (Working Paper Series, 26461).

HU, Y.; KEMP, M. C.; SHIMOMURA, K. A two-country dynamic heckscher-ohlin model with physical and human capital accumulation. Economic Theory, Springer, v. 41, n. 1, p. 67-84, 2009. ISSN 09382259, 14320479.

LOAYZA, N.; FAJNZYLBER, P.; CALDERóN, C. Economic Growth in Latin America and the Caribbean. [S.l.: s.n.], 2005. ISBN 9780821360910.

LOAYZA, N.; PALACIOS, L. Economic reform and progress in Latin America and the Caribbean. [S.1.], 1997.

ONIKI, H.; UZAWA, H. Patterns of trade and investment in a dynamic model of international trade. Review of Economic Studies, v. 32, n. 1, p. 15-37, 1965.

PERLA, J.; TONETTI, C.; WAUGH, M. E. Equilibrium technology diffusion, trade, and growth. American Economic Review, v. 111, n. 1, p. 73-128, January 2021.

RIVERA-BATIZ, L. A.; ROMER, P. M. Economic integration and endogenous growth. The Quarterly Journal of Economics, Oxford University Press, v. 106, n. 2, p. 531-555, 1991. ISSN 00335533, 15314650.

RODRIGUES, M. Import substitution and economic growth. Journal of Monetary Economics, Elsevier BV, v. 57, n. 2, p. 175-188, mar. 2010.

SACHS, J. D.; WARNER, A. Economic reform and the process of global integration. Brookings Papers on Economic Activity, v. 26, n. 1, 25th Anniversary Issue, p. 1-118, 1995.

SAMUELSON, P. A. International trade and the equalisation of factor prices. The Economic Journal, [Royal Economic Society, Wiley], v. 58, n. 230, p. 163-184, 1948. ISSN $00130133,14680297$.

SPOLAORE, E.; WACZIARG, R. Borders and growth. Journal of Economic Growth, v. 10, n. 4, p. 331-386, 2005.

TREFLER, D. International factor price differences: Leontief was right! Journal of Political Economy, University of Chicago Press, v. 101, n. 6, p. 961-987, 1993. ISSN 00223808, 1537534X.

VENTURA, J. Growth and interdependence. The Quarterly Journal of Economics, Oxford University Press, v. 112, n. 1, p. 57-84, 1997. ISSN 00335533, 15314650. 

Appendix 


\section{APPENDIX A - Equations}

\section{A.1 Closed-economy steady state}

As in Rodrigues (2010), the following equations characterize the closed-economy steady state:

$$
\begin{aligned}
& 1=\beta(r+1-\delta) \\
& r=p_{1} \theta_{1} k_{1}^{\theta_{1}-1} \\
& w=p_{1}\left(1-\theta_{1}\right) k_{1}^{\theta_{1}} \\
& p_{2}=n^{\frac{\gamma-1}{\gamma}} p \\
& x=K_{2}^{\theta_{2}} L_{2}^{1-\theta_{2}}-f \\
& p=\frac{1}{\gamma} \frac{r^{\theta_{2}}}{\theta_{2}^{\theta_{2}}} \frac{w^{1-\theta_{2}}}{\left(1-\theta_{2}\right)^{1-\theta_{2}}} \\
& x=\frac{\gamma}{1-\gamma} f \\
& \frac{w}{r}=\frac{1-\theta_{2}}{\theta_{2}} k_{2} \\
& p_{1}^{\omega} p_{2}^{(1-\omega)}=\omega^{\omega}(1-\omega)^{1-\omega} \\
& \frac{p_{1}}{p_{2}}=\frac{\omega}{(1-\omega)} \frac{Y_{2}}{Y_{1}} \\
& N(c+\delta k)=Y_{1}^{\omega} Y_{2}^{1-\omega} \\
& Y_{2}=n^{\frac{1}{\gamma}} x
\end{aligned}
$$




$$
\begin{gathered}
K_{1}+n K_{2}=N k \\
L_{1}+n L_{2}=N
\end{gathered}
$$

\section{A.2 Open-economy steady state}

Considering Proposition 2, the following equations characterize the open-economy steady state:

$$
\begin{aligned}
& 1=\beta\left(r_{\text {open }}+1-\delta\right) \\
& r_{\text {open }}=p_{1 \text { open }} \theta_{1} k_{1 \text { open }}^{\theta_{1}-1} \\
& w_{\text {open }}=p_{1 \text { open }}\left(1-\theta_{1}\right) k_{1 \text { open }}^{\theta_{1}} \\
& p_{\text {2open }}=n_{\text {open }}^{\frac{\gamma-1}{\gamma}} p_{\text {open }} \\
& x=K_{2 \text { open }}^{\theta_{2}} L_{2 \text { open }}^{1-\theta_{2}}-f \\
& p_{\text {open }}=\frac{1}{\gamma} \frac{r_{\text {open }}^{\theta_{2}}}{\theta_{2}^{\theta_{2}}} \frac{w_{\text {open }}^{1-\theta_{2}}}{\left(1-\theta_{2}\right)^{1-\theta_{2}}} \\
& x=\frac{\gamma}{1-\gamma} f \\
& \frac{w_{\text {open }}}{r_{\text {open }}}=\frac{1-\theta_{2}}{\theta_{2}} k_{2 \text { open }} \\
& p_{1 \text { open }}^{\omega} p_{2 \text { open }}^{1-\omega}=\omega^{\omega}(1-\omega)^{1-\omega} \\
& \frac{p_{1 \text { open }}}{p_{\text {2open }}}=\frac{\omega}{(1-\omega)} \frac{Y_{2 \text { open }}}{Y_{1 \text { open }}}=\frac{\omega}{(1-\omega)} \frac{Y_{2 \text { open }}^{*}}{Y_{1 \text { open }}^{*}} \\
& N\left(c_{\text {open }}+\delta k_{\text {open }}\right)=Y_{1 \text { open }}^{\omega} Y_{2 \text { open }}^{1-\omega}
\end{aligned}
$$




$$
\begin{aligned}
& N^{*}\left(c_{\text {open }}^{*}+\delta k_{\text {open }}^{*}\right)=Y_{1 \text { open }}^{* \omega} Y_{2 o p e n}^{* 1-\omega} \\
& Y_{\text {2open }}=\left(n_{\text {open }}+n_{\text {open }}^{*}\right)^{\frac{1}{\gamma}} x_{\text {open }}^{d} \\
& Y_{\text {open }}^{*}=\left(n_{\text {open }}+n_{\text {open }}^{*}\right)^{\frac{1}{\gamma}} x_{\text {open }}^{* d} \\
& p_{1 \text { open }} Y_{1 \text { open }}+p_{\text {open }}\left(n_{\text {open }}+n_{\text {open }}^{*}\right) x_{\text {open }}^{d}=p_{1 \text { open }} K_{1 \text { open }}^{\theta_{1}} L_{1 \text { open }}^{1-\theta_{1}}+p_{\text {open }} n_{\text {open }} x \\
& p_{1 \text { open }} Y_{1 \text { open }}^{*}+p_{\text {open }}\left(n_{\text {open }}+n_{\text {open }}^{*}\right) x_{\text {open }}^{* d}=p_{1 \text { open }} K_{1 \text { open }}^{* \theta_{1}} L_{1 \text { open }}^{* 1-\theta_{1}}+p_{\text {open }} n_{\text {open }}^{*} x \\
& Y_{1 \text { open }}+Y_{1 \text { open }}^{*}=K_{1 \text { open }}^{\theta_{1}} L_{1 \text { open }}^{1-\theta_{1}}+K_{1 \text { open }}^{* \theta_{1}} L_{1 \text { open }}^{* 1-\theta_{1}} \\
& K_{1 \text { open }}+n_{\text {open }} K_{2 \text { open }}=N k_{\text {open }} \\
& K_{1 \text { open }}^{*}+n_{\text {open }}^{*} K_{\text {2open }}=N_{\text {open }}^{*} k_{\text {open }}^{*} \\
& L_{1 \text { open }}+n_{\text {open }} L_{2 o p e n}=N \\
& L_{1 \text { open }}^{*}+n_{\text {open }}^{*} L_{2 \text { open }}=N^{*} \\
& x=x_{\text {open }}^{d}+x_{\text {open }}^{* d}
\end{aligned}
$$




\section{APPENDIX B - Proofs}

Proof of Corollary 1: According to Rodrigues (2010), we can express $w(N)$ as:

$$
w(N)=r \frac{\left(1-\theta_{2}\right)}{\theta_{2}}\left(\frac{V}{N} n(N)\right)^{\frac{1}{\theta_{2}}}=r \frac{\left(1-\theta_{2}\right)}{\theta_{2}}\left(V T_{n}\right)^{\frac{1}{\theta_{2}}} N^{\frac{(1-\gamma)(1-\omega)}{\gamma(1-\omega \theta 1)-(1-\omega) \theta 2}}
$$

where $V=\frac{\frac{(1-\theta 1)}{\gamma(1-\theta 2)}+\frac{(1-\omega)}{\omega x}(x+f)}{\frac{(1-\omega)}{\omega x}}$. Thus, due to Assumption 1 , we have that $w(N)$ is an increasing function of $N$.

Proof of Proposition 4: Assume, without loss of generality, that $N^{*}>N$. Thus, from Proposition $1, k^{*}\left(N^{*}\right)>k(N)$. Considering that the economies are open to trade at period 1, we have that $c_{1}^{*}>c_{1}$ because of equation (2.30). From the Euler equation $(2.15)$ :

$$
\frac{c_{t+1}^{*}}{c_{t}^{*}}=\frac{c_{t+1}}{c_{t}}=\left(\beta\left(r_{t+1}+(1-\delta)\right)\right), \forall t=1,2 \ldots
$$

Fix $\epsilon=c_{1}^{*}-c_{1}$. Therefore, $\epsilon>0$. Also, note that:

$$
\frac{c_{t}^{*}}{c_{1}^{*}}=\frac{c_{t}}{c_{1}}, \forall t=1,2, \ldots
$$

From the last equality, $\frac{c_{t}^{*}-c_{t}}{c_{1}^{*}-c_{1}}=\frac{c_{t}}{c_{1}}$, so:

$$
c_{t}^{*}-c_{t}=\frac{c_{t}}{c_{1}} \epsilon>0
$$

In the open-economy steady state:

$$
c_{\text {open }}^{*}-c_{\text {open }}=\frac{c_{\text {open }}}{c_{1}} \epsilon>0
$$

Moreover, we know that $c_{\text {open }}=w(1)+(r-\delta) k_{\text {open }}$. So:

$$
(r-\delta)\left(k_{\text {open }}^{*}-k_{\text {open }}\right)=c_{\text {open }}^{*}-c_{\text {open }}>0
$$

From the previous inequality, $k_{\text {open }}^{*}-k_{\text {open }}>0$.

Finally, $y_{\text {open }}=w(1)+r k_{\text {open }}<w(1)+r k_{\text {open }}^{*}=y_{\text {open }}^{*}$. 
Lemma 1: 1) If $N \in(0,1 / 2), k_{\text {open }} / k(N)>k_{\text {open }}^{*} / k^{*}\left(N^{*}\right)$.

2) If $N \in(1 / 2,1), k_{\text {open }} / k(N)<k_{\text {open }}^{*} / k^{*}\left(N^{*}\right)$.

3) If $N=1 / 2, k_{\text {open }} / k(N)=k_{\text {open }}^{*} / k^{*}\left(N^{*}\right)$.

Proof of Lemma 1: 1) We will only prove item 1, the other two cases are analogous. Assume that $N \in(0,1 / 2)$ and $T W_{t}=\sum_{i=t+1}^{+\infty}\left(\prod_{j=t+1}^{i} \frac{1}{r_{j}+1-\delta}\right) w_{i}+w_{t}$. Using equation 2.29 and the budget constraint of households, $k_{t+1}=w_{t}+\left(r_{t}+1-\delta\right) k_{t}-(1-$ $\beta)\left(T W_{t}+\left(r_{t}+1-\delta\right) k_{t}\right)$. Therefore, $k_{t+1}^{*}-k_{t+1}=\beta\left(r_{t}+1-\delta\right)\left(k_{t}^{*}-k_{t}\right)$.

For $t \geq 3$, it is possible to show that:

$$
k_{t+1}^{*}-k_{t+1}=\frac{c_{t}}{c_{1}} \beta\left(r_{1}+1-\delta\right)\left(k(N)^{*}-k(N)\right)
$$

In the open-economy steady state, $k_{\text {open }}^{*}-k_{\text {open }}=\frac{c_{o p e n}}{c_{1}} \beta\left(r_{1}+1-\delta\right)\left(k(N)^{*}-k(N)\right)$. From the last equality, it is possible to obtain that:

$$
k_{\text {open }}^{*}-\frac{c_{\text {open }}}{c_{1}} \beta\left(r_{1}+1-\delta\right) k^{*}\left(N^{*}\right)=k_{\text {open }}-\frac{c_{\text {open }}}{c_{1}} \beta\left(r_{1}+1-\delta\right) k(N)
$$

Therefore, $k_{\text {open }} / k(N)>k_{\text {open }}^{*} / k^{*}\left(N^{*}\right)$.

Proof of Proposition 5: We assume, without loss of generality, that $N \in(0,1 / 2)$. The same argument with small adjustments can be used for the case in which $N \in(1 / 2,1)$. From the fact that the world capital stock is a weighted arithmetic mean of the capital per capita stocks of both countries and Proposition 4, it is possible to observe that $k_{\text {open }}^{*}>k(1)>k\left(N^{*}\right)$. From Lemma $1, k_{\text {open }} / k(N)>k_{\text {open }}^{*} / k^{*}\left(N^{*}\right)>1$, which implies that $k_{\text {open }}>k(N)$.

Observing that $y_{\text {open }}=w(1)+r k_{\text {open }}$ and $y(N)=w(N)+r k(N)$, we have that $y_{\text {open }}>y(N)$. The same inequality is valid for Foreign.

Finally, for consumption, we have that $c_{\text {open }}=w(1)+(r-\delta) k_{\text {open }}$ and $c(N)=$ $w(N)+(r-\delta) k(N)$. Thus, $c_{\text {open }}>c(N)$. The same inequality is valid for Foreign.

For the case in which $N=1 / 2$, we know that $k_{\text {open }}=k_{\text {open }}^{*}$ because of Corollary 2 . Besides, considering the market clearing condition for the world capital $\left(N k_{\text {open }}+\right.$ $\left.N^{*} k_{\text {open }}^{*}=k(1)\right)$, we have that $k_{\text {open }}=k_{\text {open }}^{*}=k(1)$. Observing that $y_{\text {open }}=y(1)$ and $c_{\text {open }}=c(1)$, we have that $y_{\text {open }}>y(1 / 2)$ and $c_{\text {open }}>c(1 / 2)$. Similarly, we can obtain the same inequalities for Foreign. 
Proof of Proposition 6: 1) Assume that $N=1 / 2$. From Proposition $1, k(N) / y(N)=$ $T_{k} / T_{y}$. In the open-economy steady state, we know that $k_{\text {open }}=k(1)$. Since $y_{\text {open }}=$ $y(1)$, we have that $k(1) / y(1)=T_{k} / T_{y}$. Therefore, $k_{\text {open }} / y_{\text {open }}=k(N) / y(N)$.

Additionally, we know that $c_{\text {open }} / y_{\text {open }}=1-\delta k_{\text {open }} / y_{\text {open }}$ and $c(N) / y(N)=1-$ $\delta k(N) / y(N)$. So:

$$
\frac{c_{\text {open }}}{y_{\text {open }}}=1-\delta \frac{k_{\text {open }}}{y_{\text {open }}}=1-\delta \frac{k(N)}{y(N)}=\frac{c(N)}{y(N)}
$$

2) Assume that $N \in(0,1 / 2)$. We know that $k(N) / y(N)=T_{k} / T_{y}$. From Proposition 5 , we can observe that $k_{\text {open }}<k(1)$. Therefore, we have that:

$$
\frac{1}{\frac{w(1)}{k_{\text {open }}}+r}<\frac{1}{\frac{w(1)}{k(1)}+r}=\frac{T_{k}}{T_{y}}
$$

From the relations above, $k_{\text {open }} / y_{\text {open }}<k(N) / y(N)$.

Moreover, we have that:

$$
\frac{c_{\text {open }}}{y_{\text {open }}}=1-\delta \frac{k_{\text {open }}}{y_{\text {open }}}>1-\delta \frac{k(N)}{y(N)}=\frac{c(N)}{y(N)}
$$

3) Assume that $N \in(1 / 2,1)$. We know that $k_{\text {open }}>k(1)$. Thus, using the same argument from the previous item, we can obtain that $k_{\text {open }} / y_{\text {open }}>k(N) / y(N)$.

Finally, we have that:

$$
\frac{c_{\text {open }}}{y_{\text {open }}}=1-\delta \frac{k_{\text {open }}}{y_{\text {open }}}<1-\delta \frac{k(N)}{y(N)}=\frac{c(N)}{y(N)}
$$

Proof of Proposition 7: 1) We will only prove item 1, the other two items are analogous. Assume that $N \in(0,1 / 2)$. From Lemma 1 , we have that $k_{\text {open }} / k(N)>k_{\text {open }}^{*} / k^{*}\left(N^{*}\right)$. Furthermore, we know that the following relations are valid:

$$
\frac{N_{c}}{N}>\frac{N_{y}}{N}>\frac{N_{k}}{N}>\frac{N_{k}^{*}}{N^{*}}>\frac{N_{y}^{*}}{N^{*}}>\frac{N_{c}^{*}}{N^{*}}
$$

Thus, we have that $N_{c} / N>N_{c}^{*} / N^{*}$ and $N_{y} / N>N_{y}^{*} / N^{*}$. That is, $c_{\text {open }} / c(N)>$ $c_{\text {open }}^{*} / c^{*}\left(N^{*}\right)$ and $y_{\text {open }} / y(N)>y_{\text {open }}^{*} / y^{*}\left(N^{*}\right)$. 
Proof of Proposition 8: Assume that $N \in(0,1 / 2]$. Firstly, we know from equation (2.31) that $A_{\text {open }}=y_{\text {open }} / k_{\text {open }}^{\alpha}$ and $A(N)=y(N) / k(N)^{\alpha}$. Moreover, it is possible to observe that $A(N)=\frac{T_{y}}{T_{k}^{\alpha}} N^{\frac{(1-\alpha)(1-\omega)(1-\gamma)}{\gamma\left(1-\omega \theta_{1}\right)-\theta_{2}(1-\omega)}}$. Also, it is valid that $N<N_{k} \leq 1$. Since $A_{\text {open }}=\left(w(1)+r k_{\text {open }}\right) / k_{\text {open }}^{\alpha}$, we have that:

$$
A_{\text {open }} \geq \frac{w\left(N_{k}\right)+r k_{\text {open }}}{k_{\text {open }}^{\alpha}}=\frac{T_{y}}{T_{k}^{\alpha}} N_{k}^{\frac{(1-\alpha)(1-\omega)(1-\gamma)}{\gamma\left(1-\omega \theta_{1}\right)-\theta_{2}(1-\omega)}}>\frac{T_{y}}{T_{k}^{\alpha}} N^{\frac{(1-\alpha)(1-\omega)(1-\gamma)}{\gamma\left(1-\omega \theta_{1}\right)-\theta_{2}(1-\omega)}}=A(N)
$$

Proof of Proposition 9: 1) Assume that $N \in(0,1 / 2)$. Assume by way of contradiction that $A_{\text {open }} / A(N) \leq A_{\text {open }}^{*} / A^{*}\left(N^{*}\right)$. Thus, we can rewrite this as $\frac{\frac{N_{y}}{N}}{\frac{N_{y}^{*}}{N^{*}}} \leq\left(\frac{\frac{N_{k}}{N}}{\frac{N_{k}^{*}}{N^{*}}}\right)^{\alpha}$. Note that $\left(\frac{\frac{N_{k}}{N}}{\frac{N_{k}^{*}}{N^{*}}}\right)^{\alpha} \leq \frac{\frac{N_{k}}{N}}{\frac{N_{k}^{*}}{N^{*}}}$. Thus, $\frac{\frac{N_{y}}{N}}{\frac{N_{y}^{*}}{N^{*}}} \leq \frac{\frac{N_{k}}{N}}{\frac{N}{N_{k}^{*}}}$. Absurd.

The other two cases are analogous.

Proof of Corollary 5: The proof will be by contradiction. We will show that the three possible cases that violate the corollary result in an absurd. Since negative values of capital per capita are not allowed, we always have that $g(k), g\left(k^{*}\right) \geq-1$. In this proof, we assume that at period 0 the countries enter in a balanced growth path, and they are open to trade.

1) In this first case, we assume by way of contradiction that one country has a growth rate of the capital per capita greater than the growth rate of the capital per capital of the world economy. We assume, without loss of generality, that $g(k)>g\left(k_{w}\right)$. From the market clearing condition for the world capital, $N_{t} k_{t}+N_{t}^{*} k_{t}^{*}=N_{w t} k_{w t}$. Considering the restriction imposed to $g\left(k^{*}\right)$, we have that $N_{t}^{*} k_{t}^{*} \geq 0$ in every period. Therefore, $N_{t} k_{t} \leq N_{w t} k_{w t}$. From the previous inequality, we have that $N_{0} k_{0}(1+g(k))^{t} \leq k_{w 0}\left(1+g\left(k_{w}\right)\right)^{t}$. Moreover, after some algebraic operations, we can obtain that $g(k) \leq\left(\left(\frac{k_{w 0}}{N_{0} k_{0}}\right)^{\frac{1}{t}}\left(1+g\left(k_{w}\right)\right)\right)-1$, which is valid in every period. Therefore, when $t \rightarrow+\infty, g(k) \leq g\left(k_{w}\right)$. Absurd. 
2) Now we assume by way of contradiction that the growth rates of the capital per capita of both countries are smaller than the growth rate of the capital per capita of the world economy (max. $\left.\left\{g(k), g\left(k^{*}\right)\right\}<g\left(k_{w}\right)\right)$. Considering the market clearing condition for the world capital, $\left(1+\max .\left\{g(k), g\left(k^{*}\right)\right\}\right)^{t}\left(N_{0} k_{0}+N_{0}^{*} k_{0}^{*}\right) \geq k_{w 0}\left(1+g\left(k_{w}\right)\right)^{t}$. However, this would imply that $\left(1+\max .\left\{g(k), g\left(k^{*}\right)\right\}\right)^{t} \geq\left(1+g\left(k_{w}\right)\right)^{t}$ in every period. Absurd.

3) Finally, we assume by way of contradiction that only one country has a growth rate of capital per capita smaller than the growth rate of the capital per capita of the world economy. We assume, without loss of generality, that $g(k)<g\left(k_{w}\right)$, but $g\left(k^{*}\right)=g\left(k_{w}\right)$. From the market clearing condition for the world capital, $N_{0} k_{0}(1+g(k))^{t}=\left(k_{w 0}-\right.$ $\left.N_{0}^{*} k_{0}^{*}\right)\left(1+g\left(k_{w}\right)\right)^{t}$. However, due to the same market clearing condition at period 0 , we have that $(1+g(k))^{t}=\left(1+g\left(k_{w}\right)\right)^{t}$. Absurd.

After observing the three cases above, we can conclude that the only possible situation for the countries when they are in a balanced growth path is $g\left(k_{w}\right)=g(k)=g\left(k^{*}\right)$. The proof for the growth rates of the other variables is similar to the one of Proposition 10, which is presented in Rodrigues (2010). 


\section{APPENDIX C - Computation of transition paths}

In this appendix, we present how we can obtain the transition paths presented in the paper. Our strategy is similar to the one used by Rodrigues (2010).

First of all, Rodrigues (2010) demonstrates that the transition path of capital per capita in a closed economy is equal to the following second-order difference equation:

$$
\frac{(1+g(k))}{\phi_{y}\left(\tilde{k}_{t}\right)-(1+g(k)) \tilde{k}_{t+1}+(1-\delta) \tilde{k}_{t}}=\frac{\beta\left(\phi_{r}\left(\tilde{k}_{t+1}\right)+1-\delta\right)}{\phi_{y}\left(\tilde{k}_{t+1}\right)-(1+g(k)) \tilde{k}_{t+2}+(1-\delta) \tilde{k}_{t+1}}
$$

considering:

$$
\begin{gathered}
\phi_{r}\left(\tilde{k}_{t}\right)=H_{r} N_{t}^{\frac{(1-\omega)(1-\gamma)}{\gamma}} \tilde{k}_{t}^{\frac{\theta_{2}(1-\omega)-\gamma\left(1-\omega \theta_{1}\right)}{\gamma}} \\
\phi_{y}\left(\tilde{k}_{t}\right)=H_{y} N_{t}^{\frac{(1-\omega)(1-\gamma)}{\gamma}} \tilde{k}_{t}^{\frac{\theta_{2}(1-\omega)-\gamma\left(1-\omega \theta_{1}\right)}{\gamma}},
\end{gathered}
$$

where $H_{y}$ and $H_{r}$ are constants.

For the simulations in which the economy is closed to trade, we assume that the initial condition is the lower limit of the cone of diversification and the final condition is the closed-economy steady state. Therefore, we consider that in the long run, which we denote by $T_{f}$ (in our simulations $T_{f}=100$ ), the economy is arbitrarily closed to the closed-economy steady state. Since we have an initial condition, a final condition and a second-order difference equation representing the transition path of capital per capita, we can solve this difference equation and obtain the transition path of capital per capita. Furthermore, from the transition path of capital per capita, we can obtain the transition paths of the other variables.

For the simulations for the case in which the economy reopens to trade, we assume that the countries are in their closed-economy steady state when they reopen their economies. Furthermore, they converge to the open-economy steady state in the long run, which we denote by $T_{o}$ (in our simulations $T_{o}=100$ ). Since we assume that during the transition between steady states both countries are in the cone of diversification, the paths of factor prices are equal for both countries. Furthermore, the paths of factor prices and the paths of the other variables for the world economy coincide with their respective transition paths for a closed economy of size 1 with the same initial condition that converges to its steady state. 
Nevertheless, with the process explained in the previous paragraph, we are only able to obtain the transition paths of the variables for the world economy. In order to obtain the transition paths for each country individually, we use a shooting algorithm. To explain this algorithm, we use the same example of Rodrigues (2010):

1. Guess a value for consumption per capita for Home at period 1, $\tilde{c_{1}}$.

2. Use the path of the rental rate of capital and the Euler equation for Home to obtain the transition path of consumption for Home $\left(\left\{\tilde{c}_{t}\right\}_{t=0}^{T_{o}}\right)$.

3. Check if the path $\left\{\tilde{c}_{t}\right\}_{t=0}^{T_{o}}$ converges. For this, consider $\epsilon>0$ as a small number and $d=\tilde{c}_{T_{o}}-\tilde{c}_{T_{o}-1}$. Hence, we have the three following possibilities:

a) In the case $|d| \leq \epsilon$, consumption converged and we can go to the next step.

b) In the case $d>\epsilon$, we have to decrease our initial guess and repeat the procedure.

c) In the case $d<-\epsilon$, we have to increase our initial guess and repeat the procedure.

4. After obtaining the path of consumption and considering the initial condition of capital per capita for Home, we can obtain the path of capital per capita for Home $\left(\left\{\tilde{k}_{t}\right\}_{t=0}^{T_{o}}\right)$ using the budget constraint of households. From this path, we can obtain the transition paths of the other variables for Home. Furthermore, to obtain the transition paths for Foreign, we only need to use the transition paths for the world economy and for Home.

5. After obtaining the transition paths for both countries, we must check if the assumption that the countries are in the cone of diversification is valid. To do this, we need to check if the quantities of capital and labor used in each sector are non-negative in every period in both countries. 


\section{APPENDIX D - Figures}

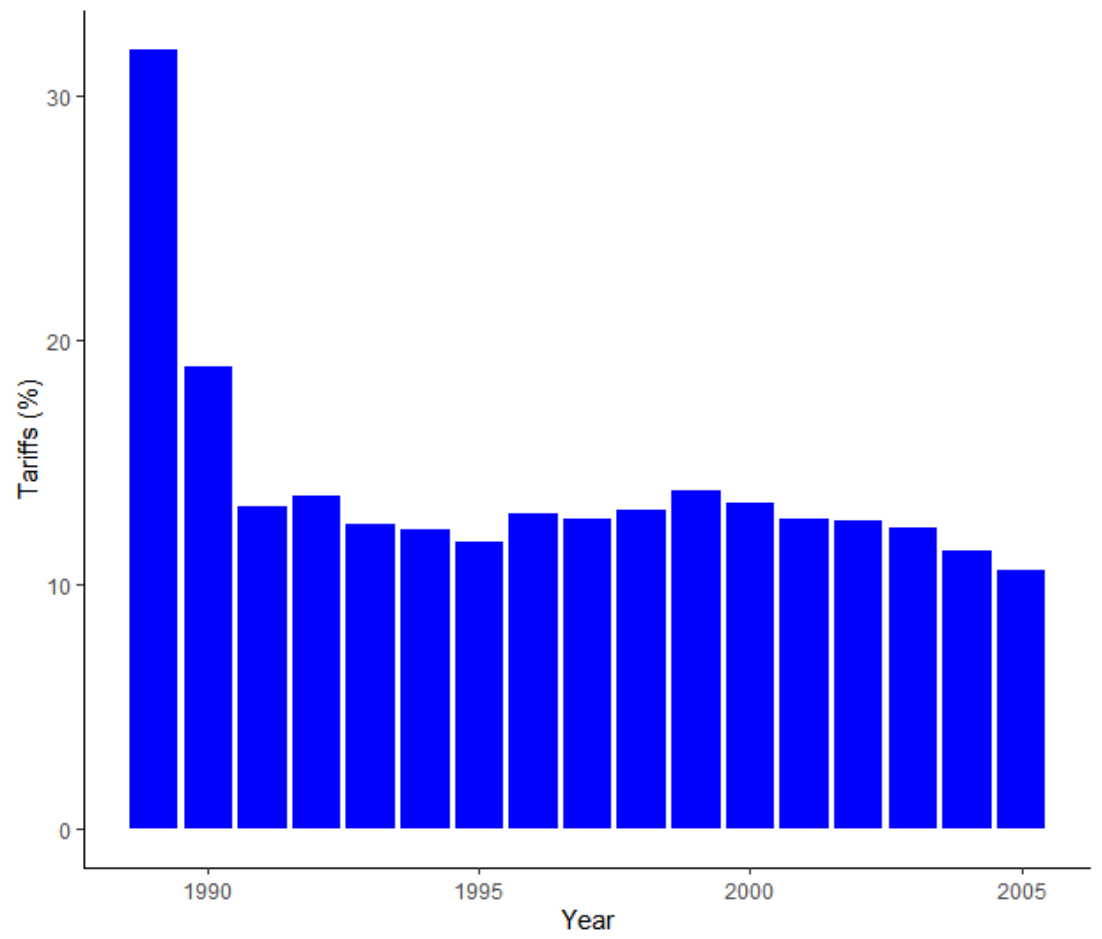

Notes: Data from World Development Indicators(Bank (2016)).

Figure 1 - Latin America's average import tariff on all products (\%) between 1989 and 2005 


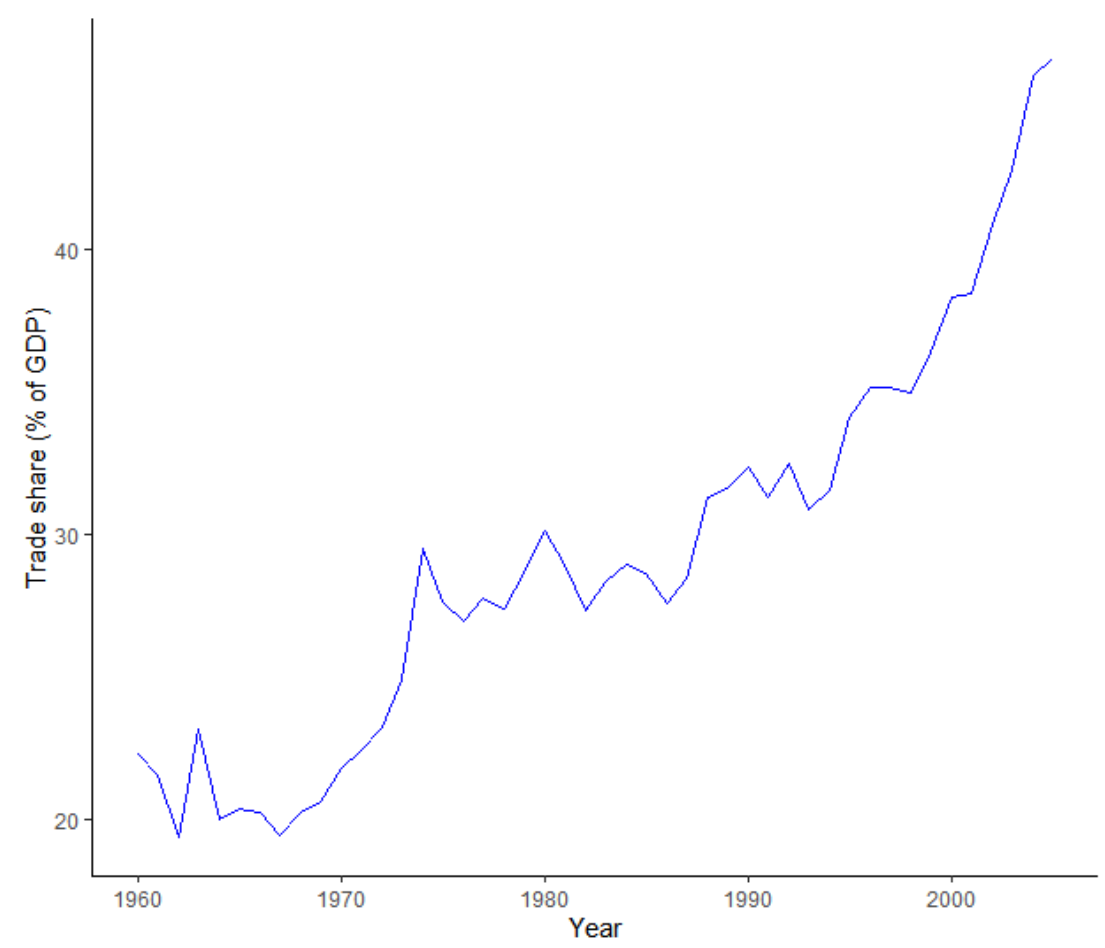

Notes: Data from World Development Indicators (Bank (2016)).

Figure 2 - Latin America's trade share (\% of GDP) between 1960 and 2005

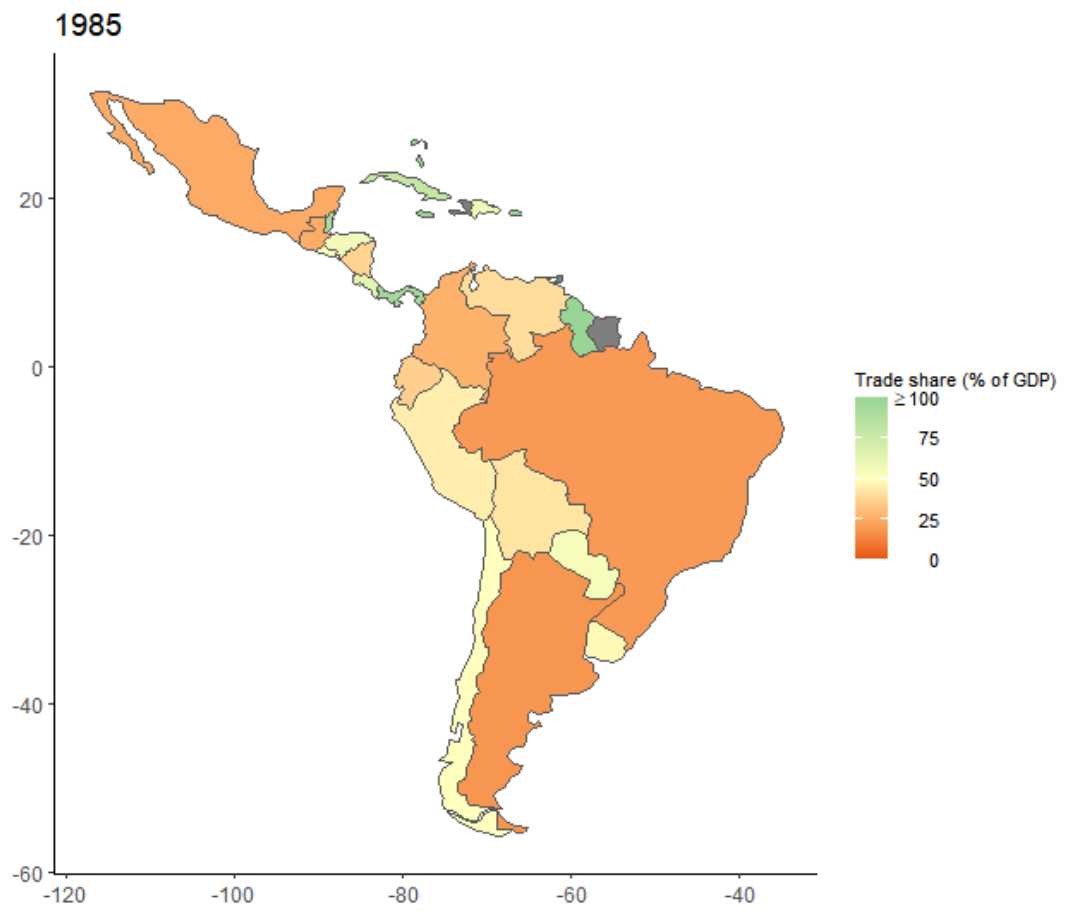

Notes: Data from World Development Indicators (Bank (2016)).

Figure 3 - Trade share (\% of GDP) in 1985 


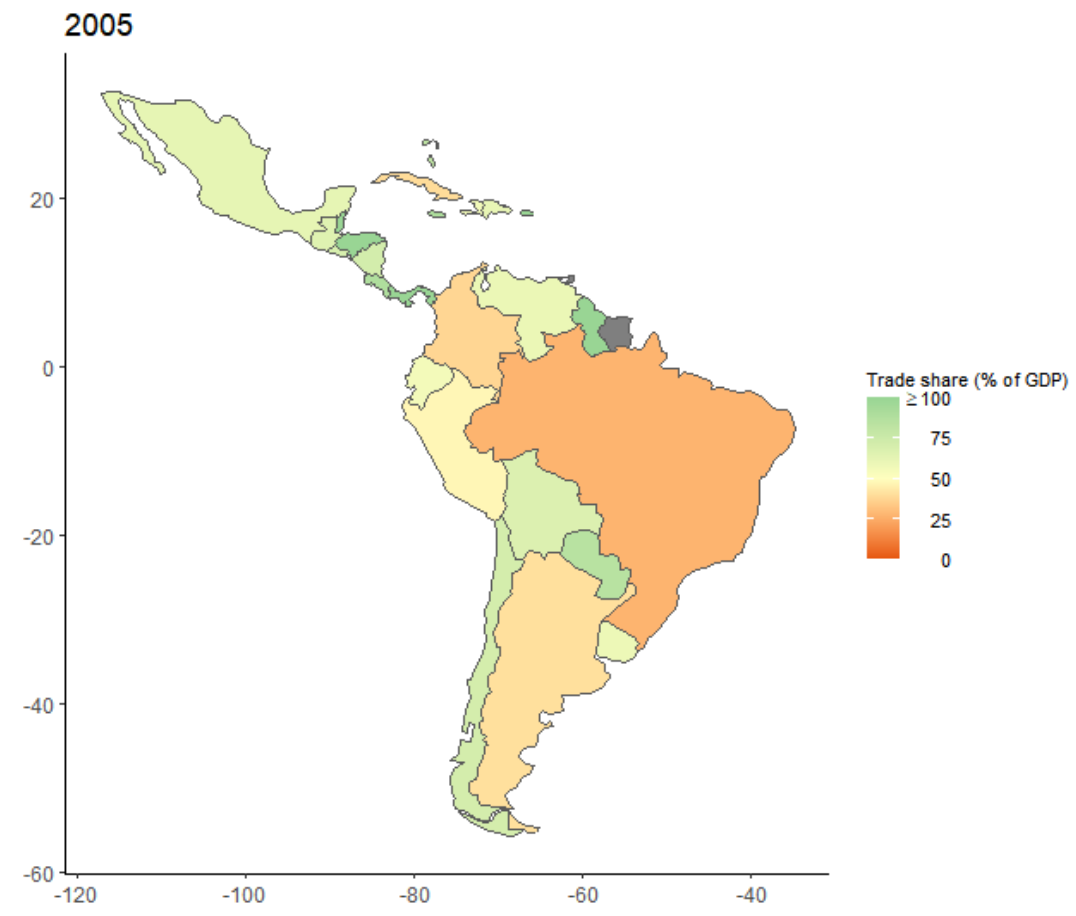

Notes: Data from World Development Indicators (Bank (2016)).

Figure 4 - Trade share (\% of GDP) in 2005

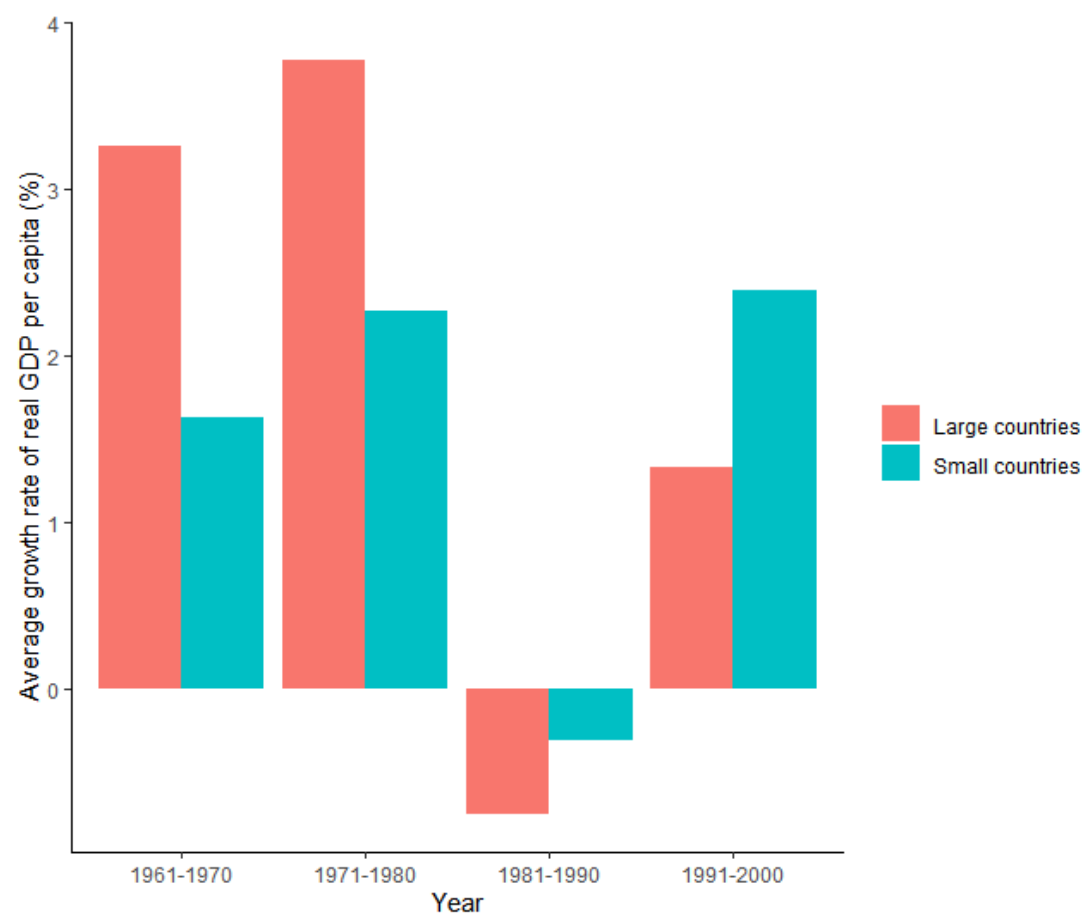

Notes: Data from PWT 9.1 (Feenstra, Inklaar and Timmer (2015)) and author's calculation. Large countries are countries with a population equal or greater than 15 million people in 1990, while small countries are countries with a population smaller than 15 million people in 1990. GDP per capita is PPP adjusted.

Figure 5 - Average real GDP per capita growth rates of small and large countries in Latin America 


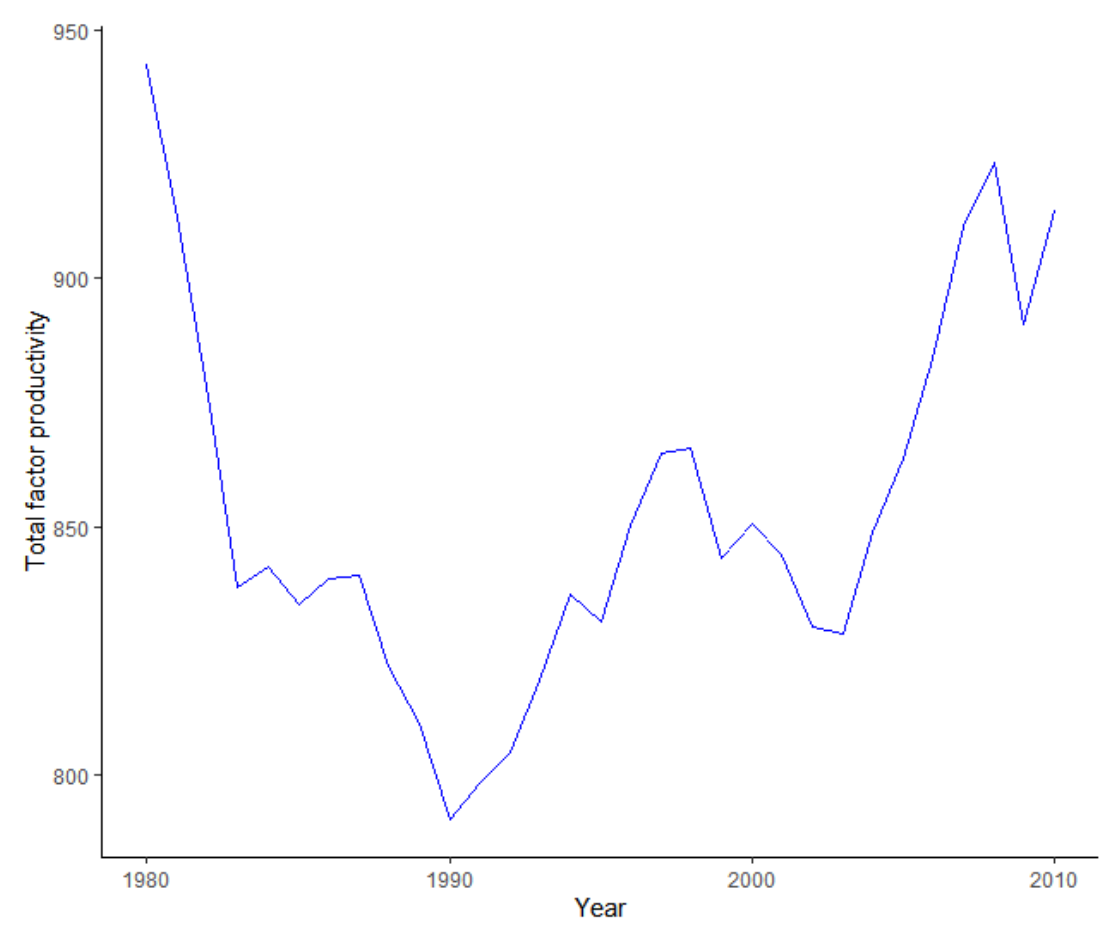

Notes: Data from PWT 9.1 (Feenstra, Inklaar and Timmer (2015)). TFP is calculated using a production function of the type $Y=A K^{\alpha} L^{1-\alpha}$, where $\alpha=0.3$.

Figure 6 - Total factor productivity of Latin America between 1980 and 2010

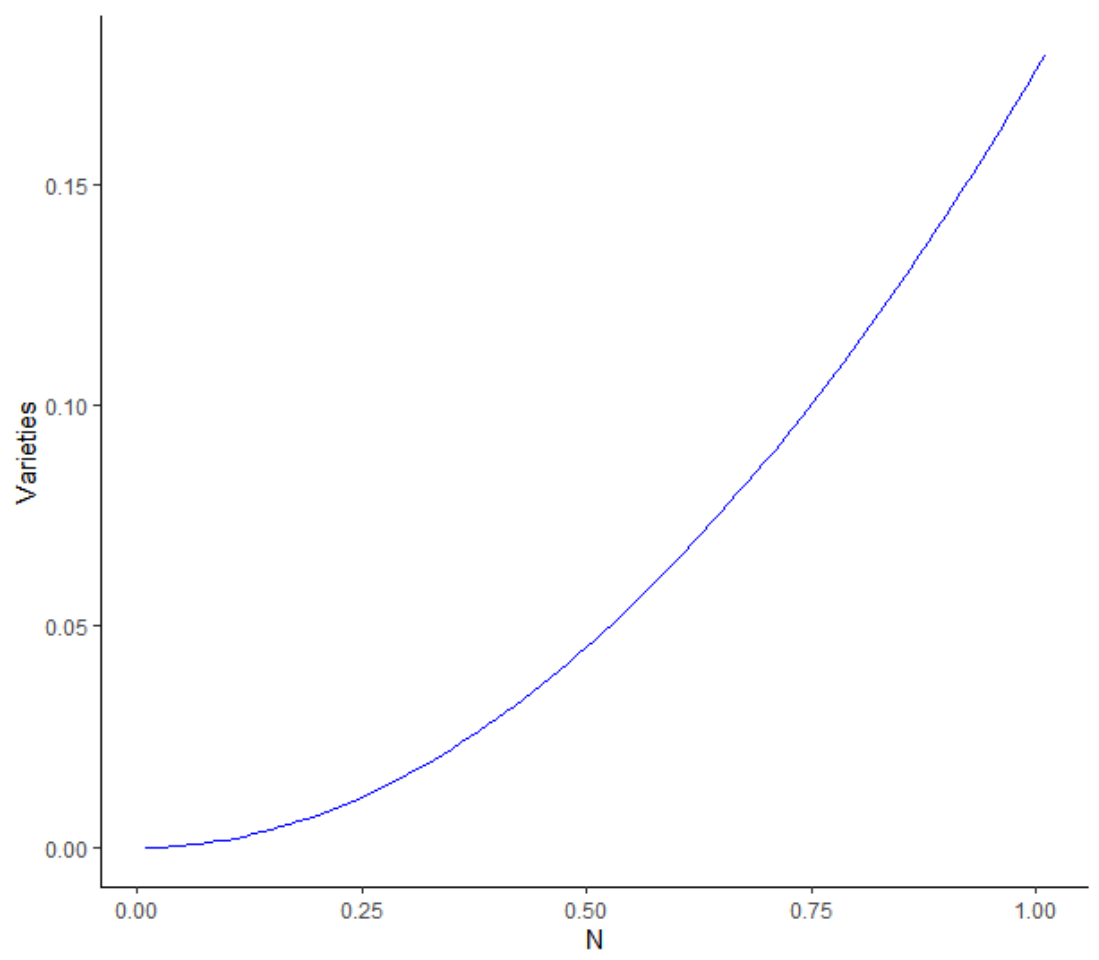

Figure 7 - Quantity of varieties produced in the closed-economy steady state as a function of $\mathrm{N}$ 


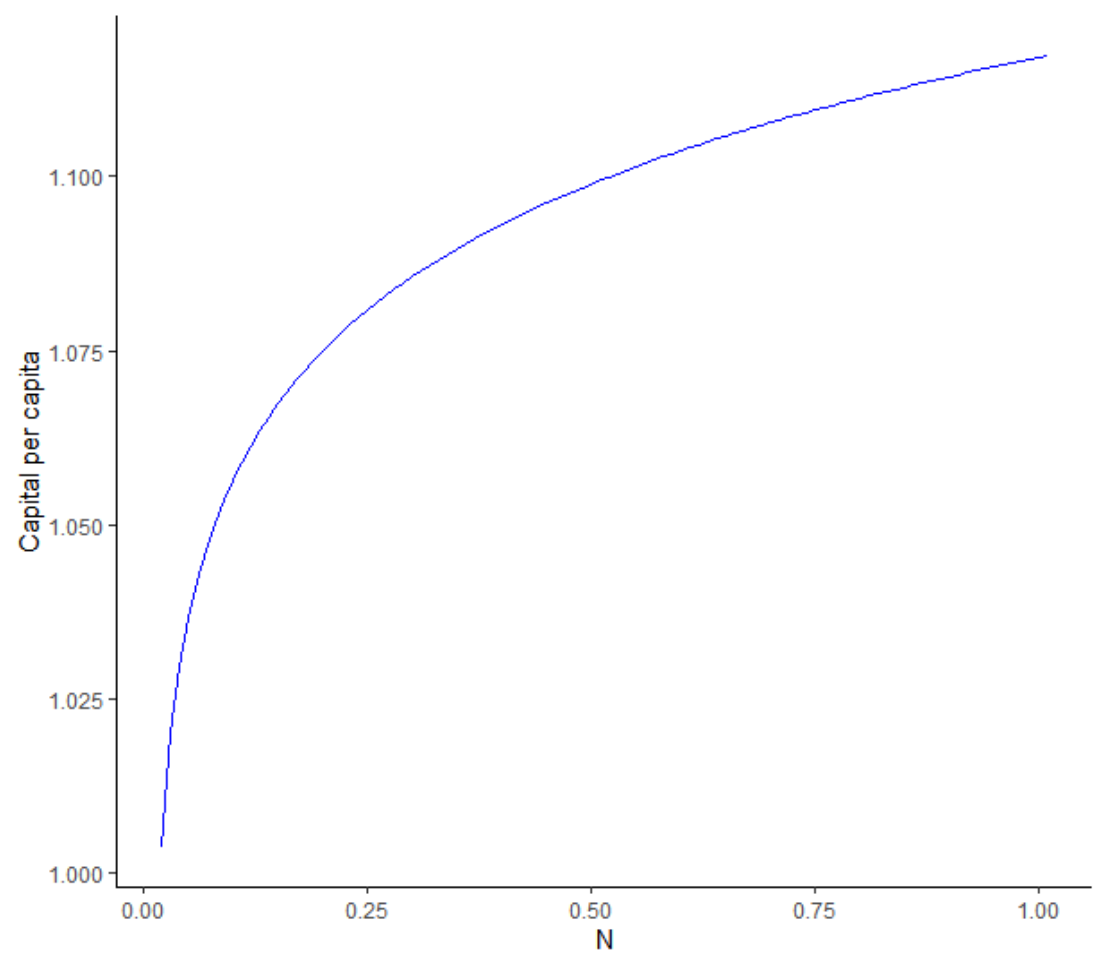

Figure 8 - Capital per capita in the closed-economy steady state as a function of $\mathrm{N}$

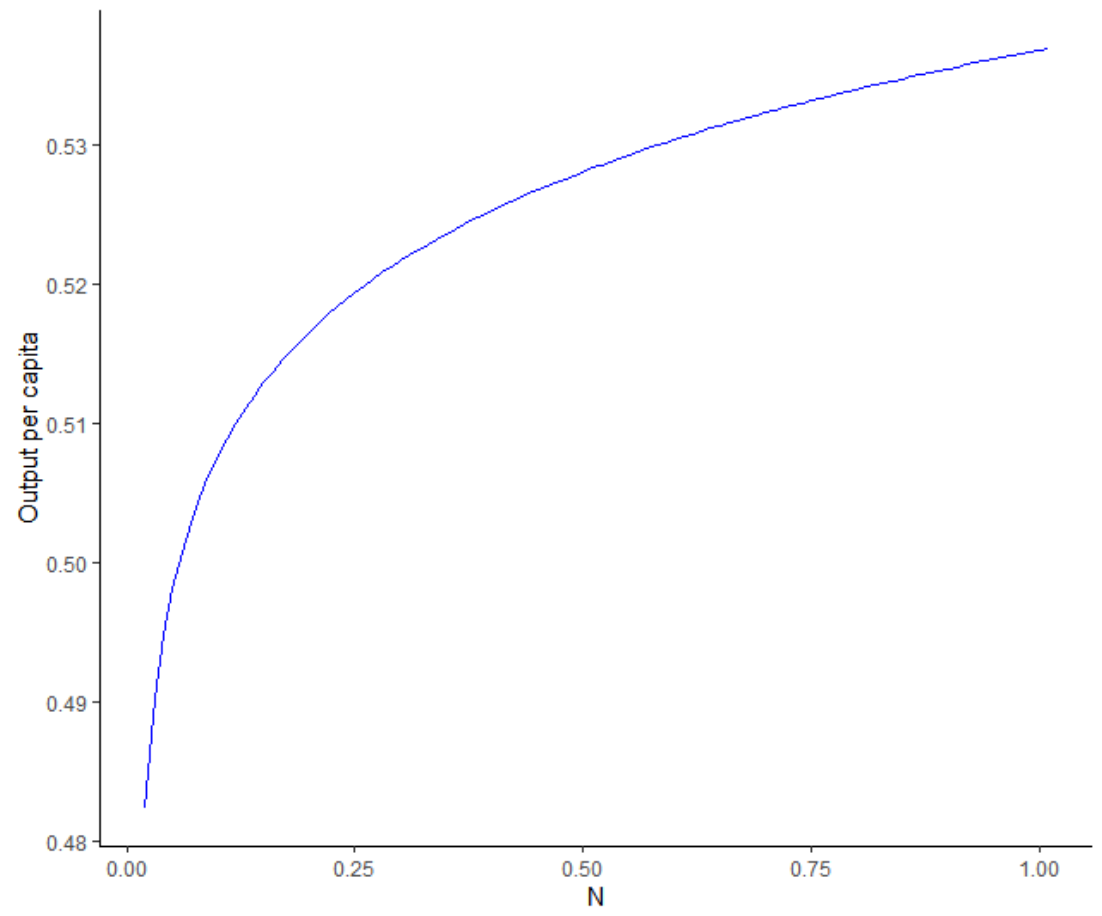

Figure 9 - Output per capita in the closed-economy steady state as a function of $\mathrm{N}$ 


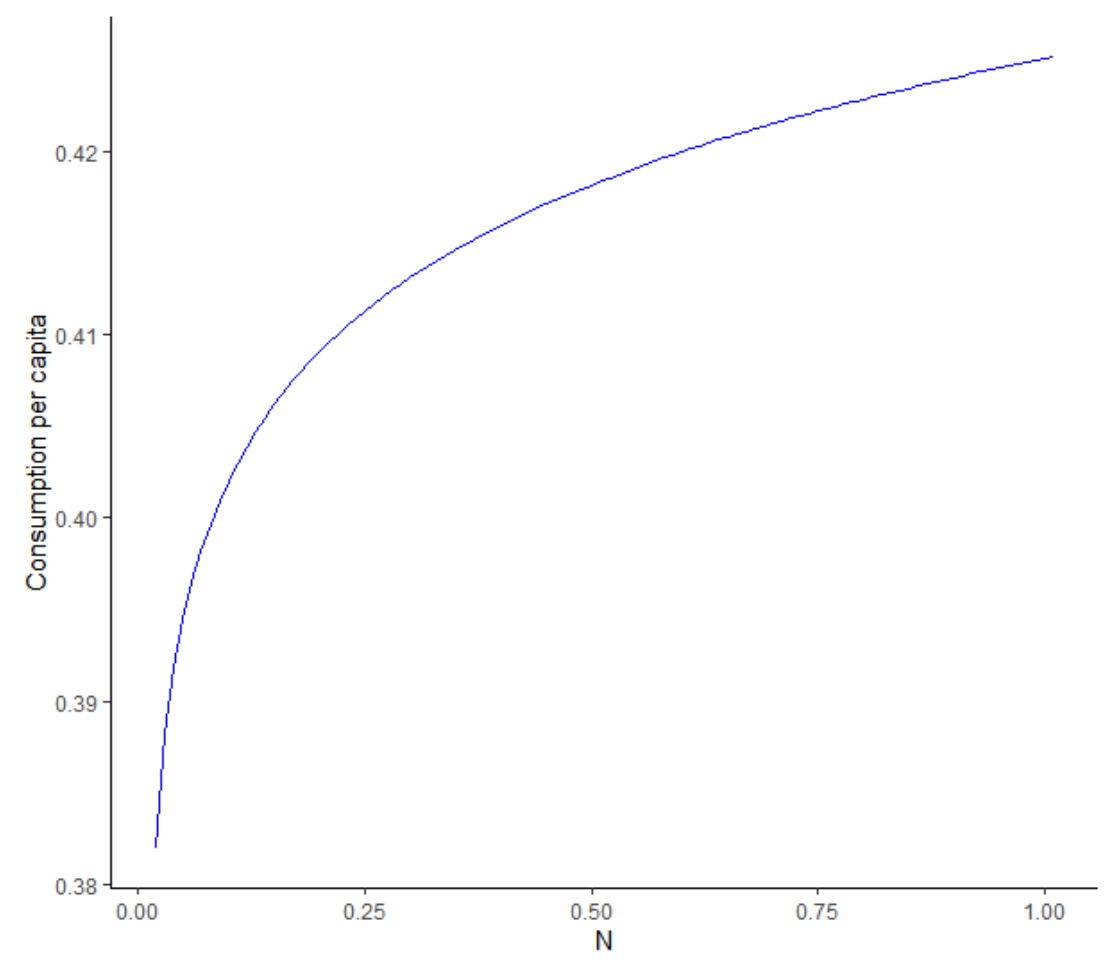

Figure 10 - Consumption per capita in the closed-economy steady state as a function of $\mathrm{N}$

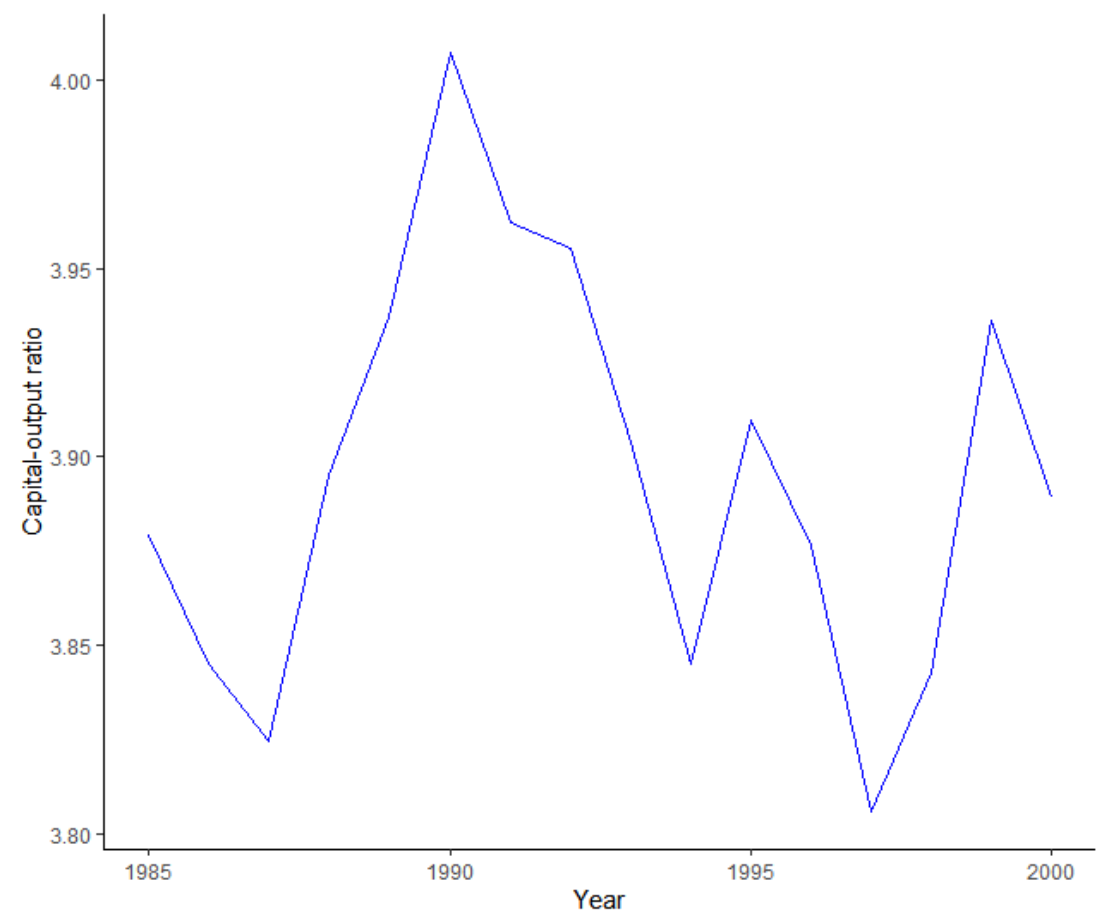

Notes: Data from PWT 9.1 (Feenstra, Inklaar and Timmer (2015)).

Figure 11 - Latin America's capital-output ratio between 1985 and 2000 


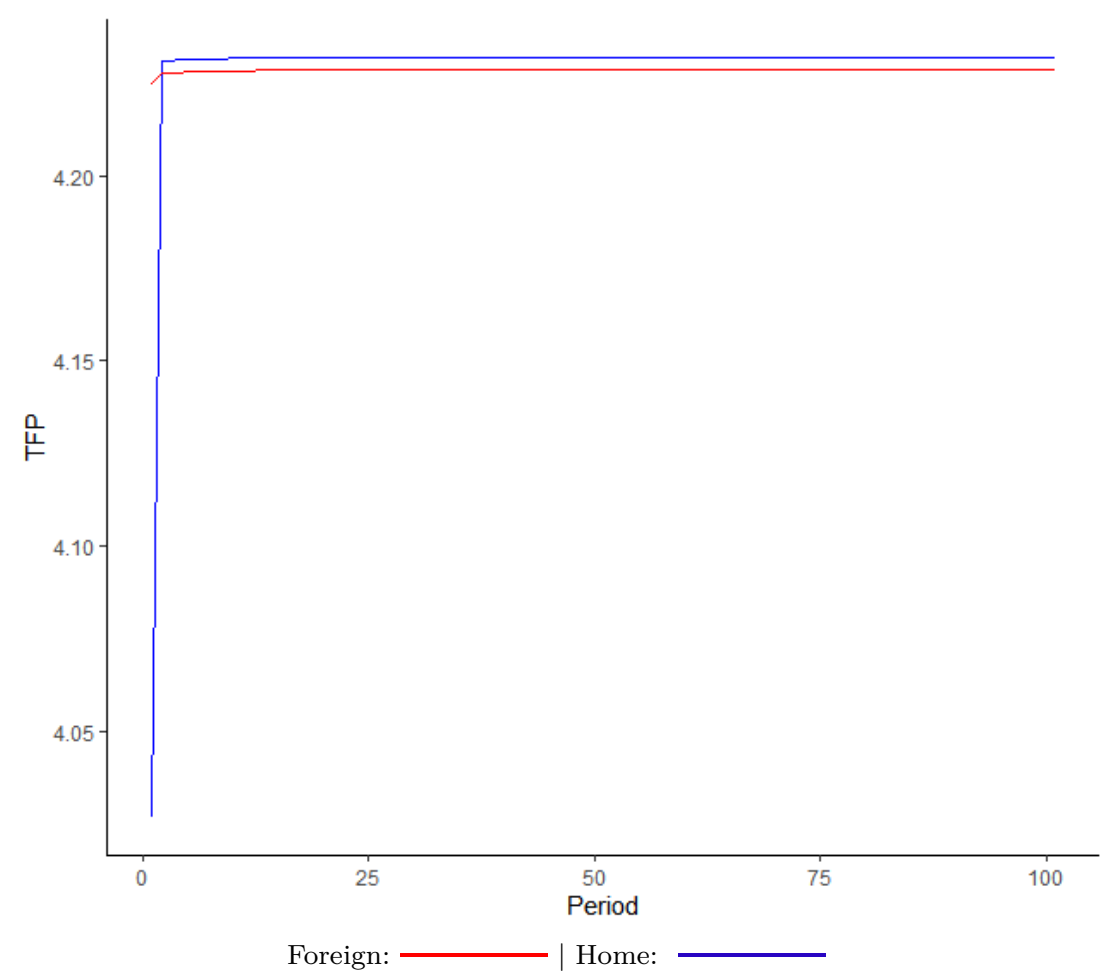

Figure 12 - Transition paths of TFP ( $\alpha=0.3$ and $N=0.05$ )

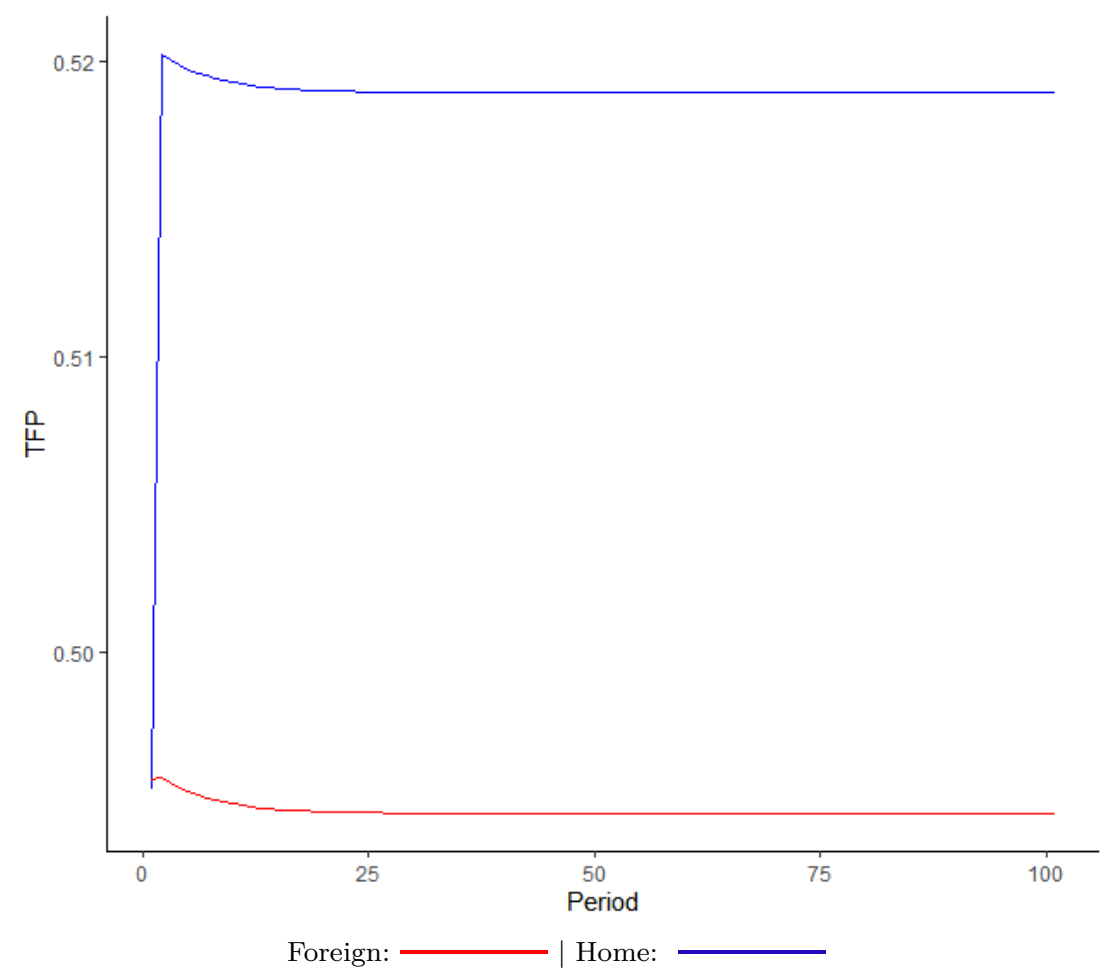

Figure 13 - Transition paths of TFP ( $\alpha=0.99$ and $N=0.05)$ 


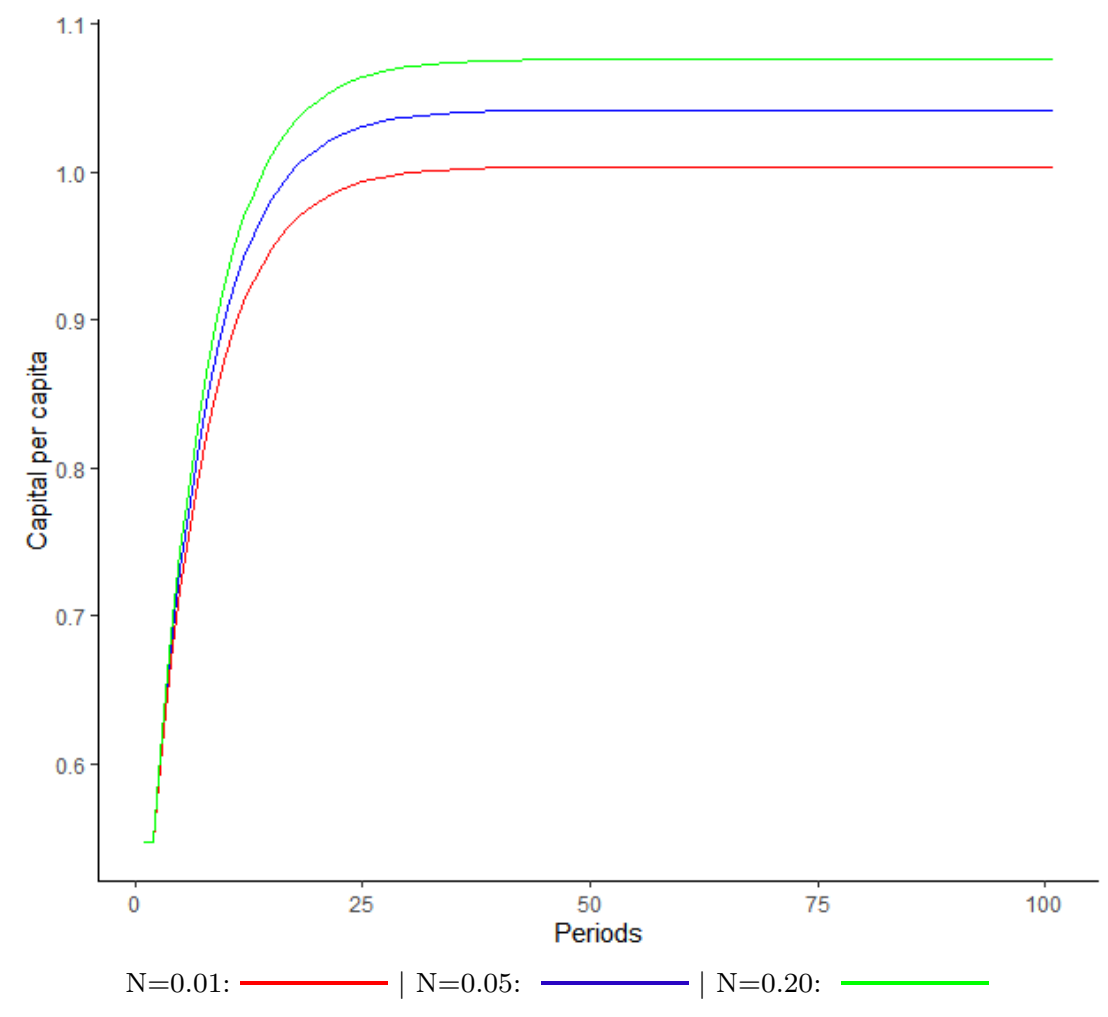

Figure 14 - Transition paths of capital per capita in the closed economy

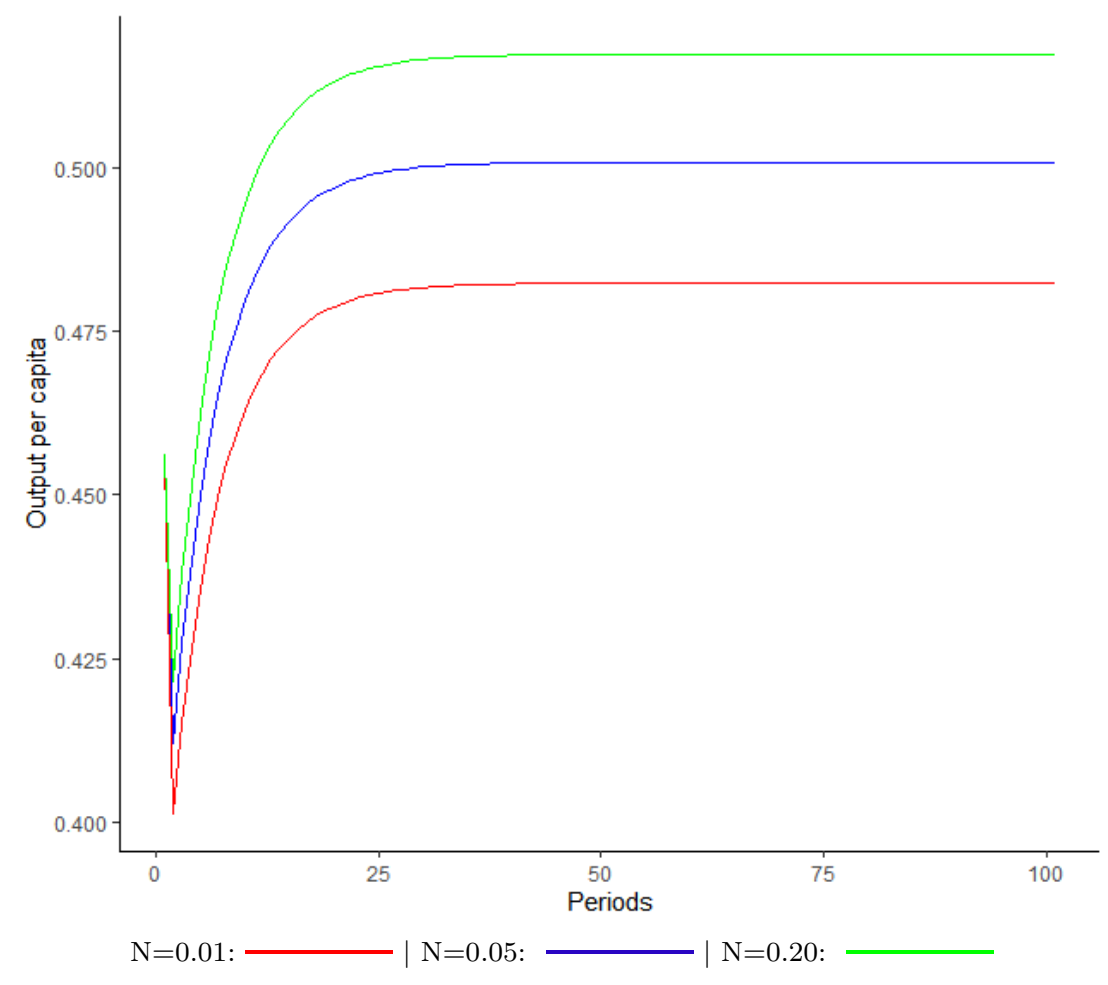

Figure 15 - Transition paths of output per capita in the closed economy 


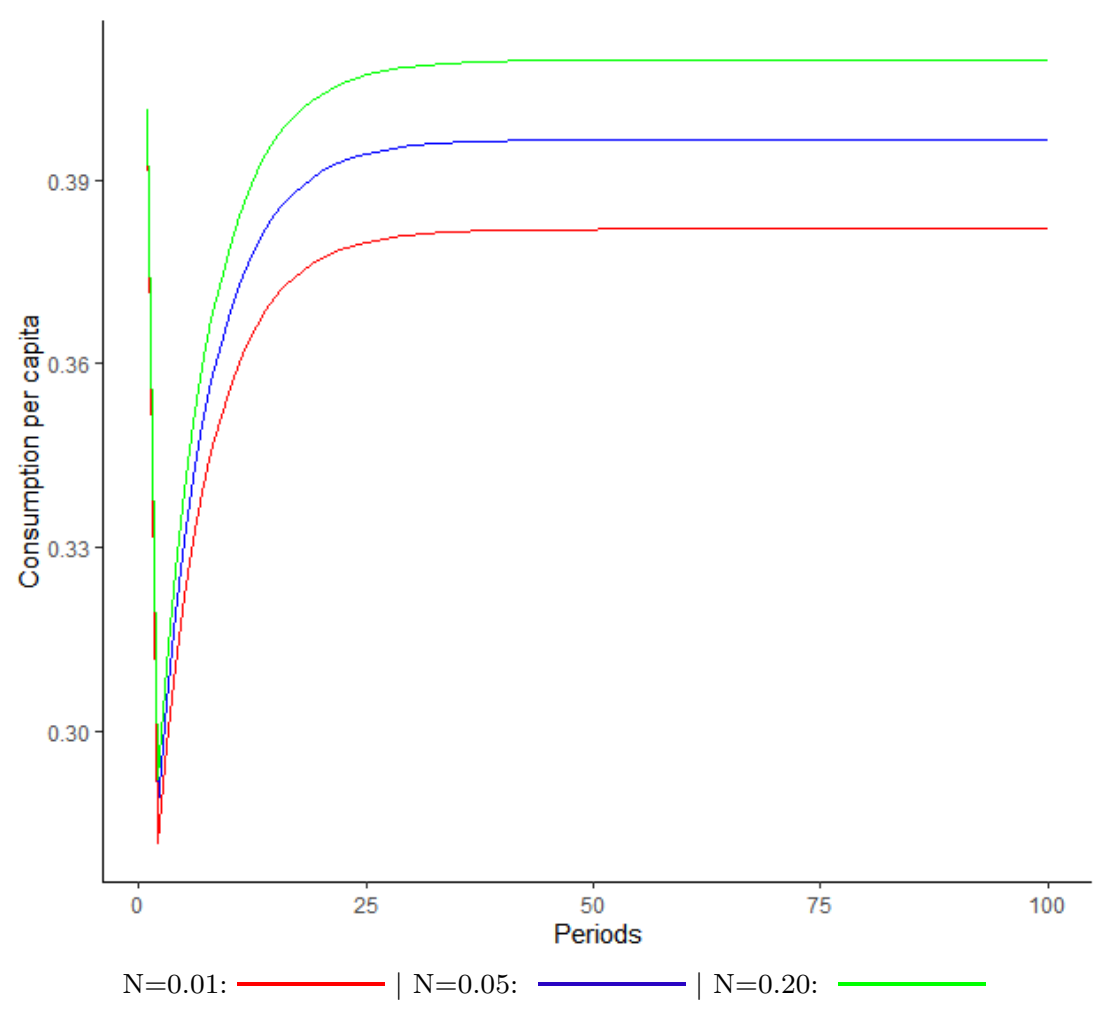

Figure 16 - Transition paths of consumption per capita in the closed economy

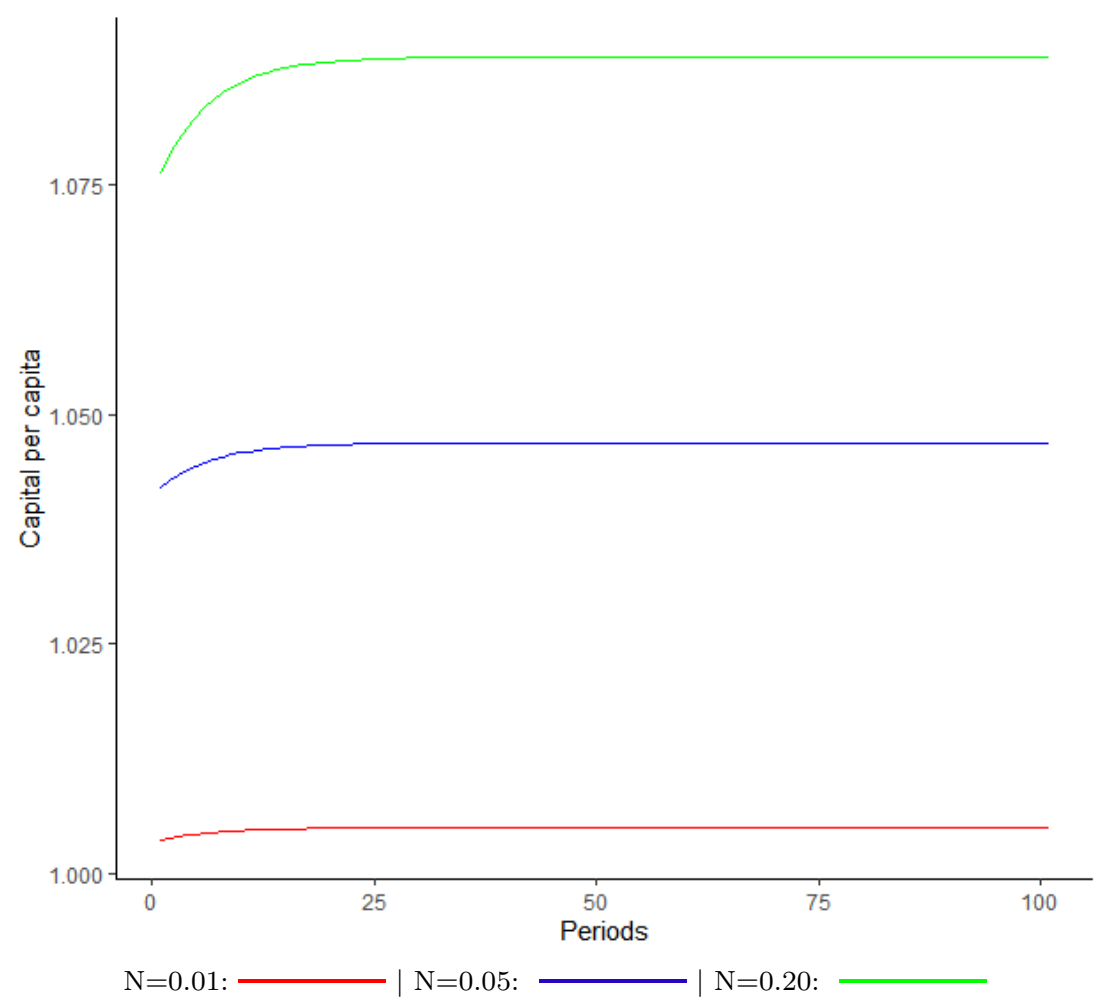

Figure 17 - Transition paths of capital per capita in the open economy 


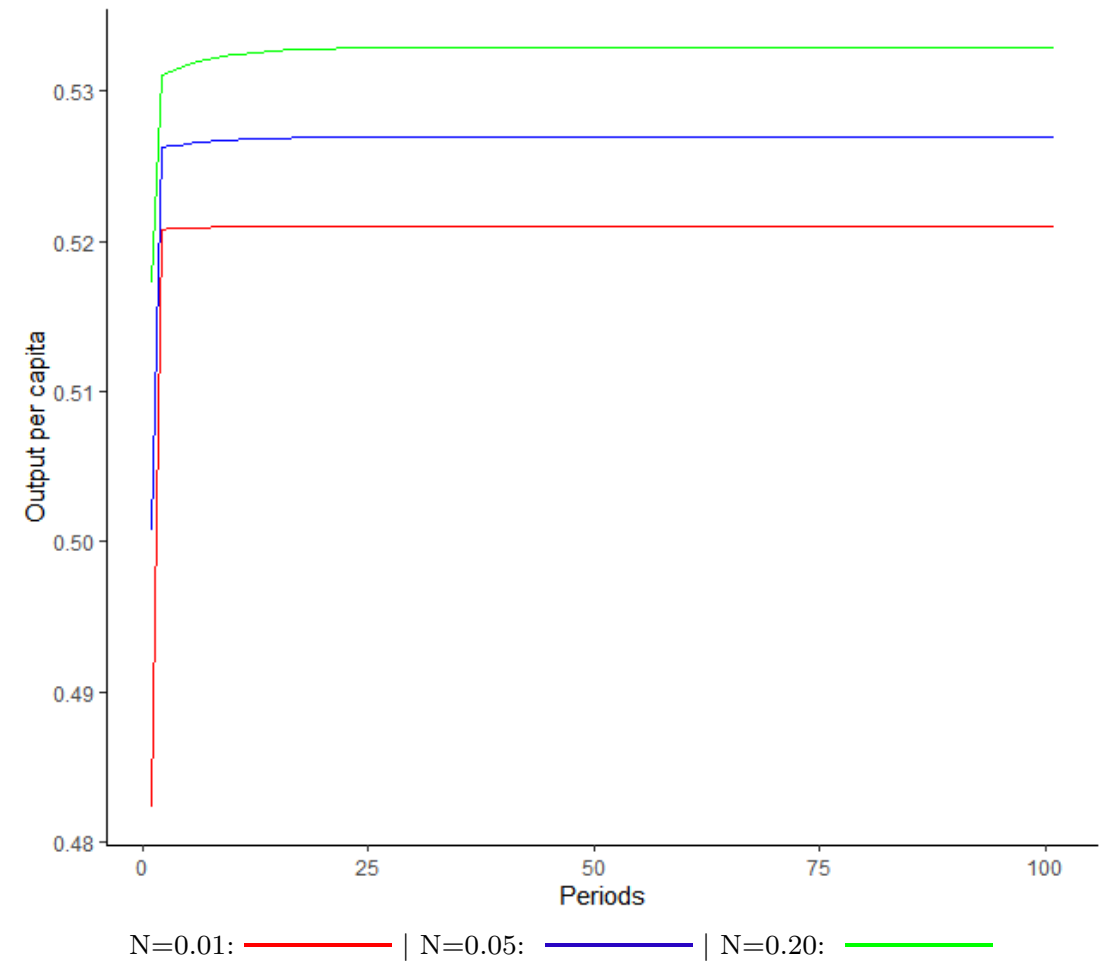

Figure 18 - Transition paths of output per capita in the open economy

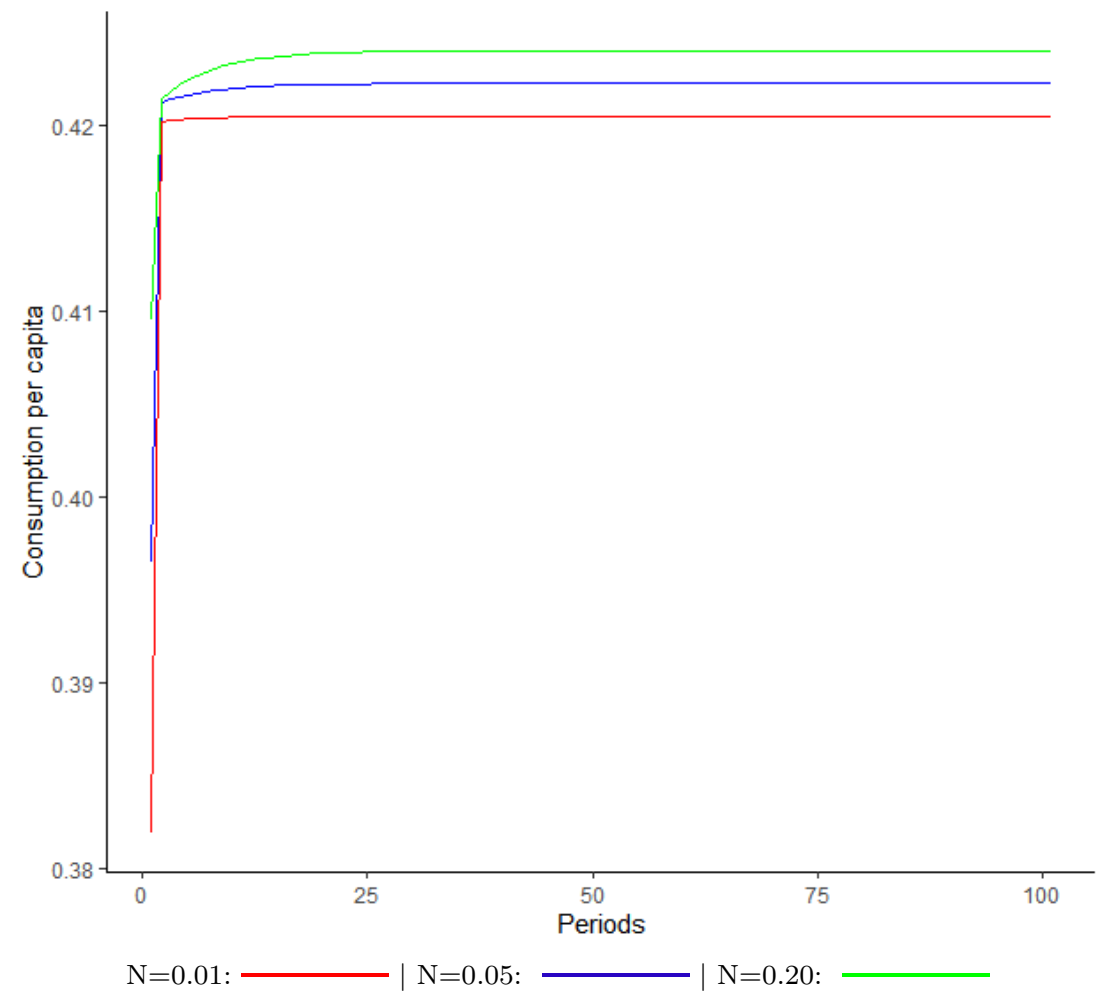

Figure 19 - Transition paths of consumption per capita in the open economy 


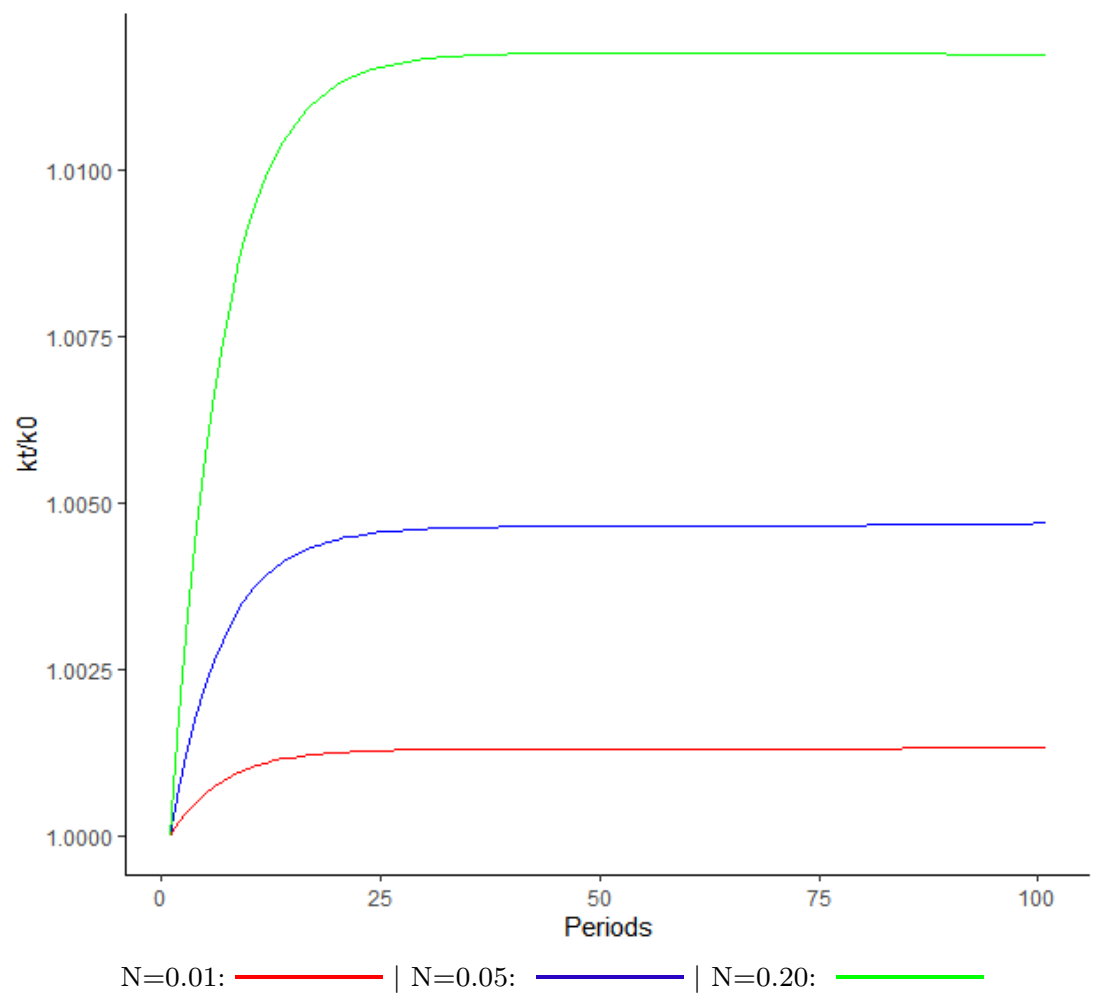

Figure 20 - Transition paths of $k_{t} / k_{0}$ in the open economy

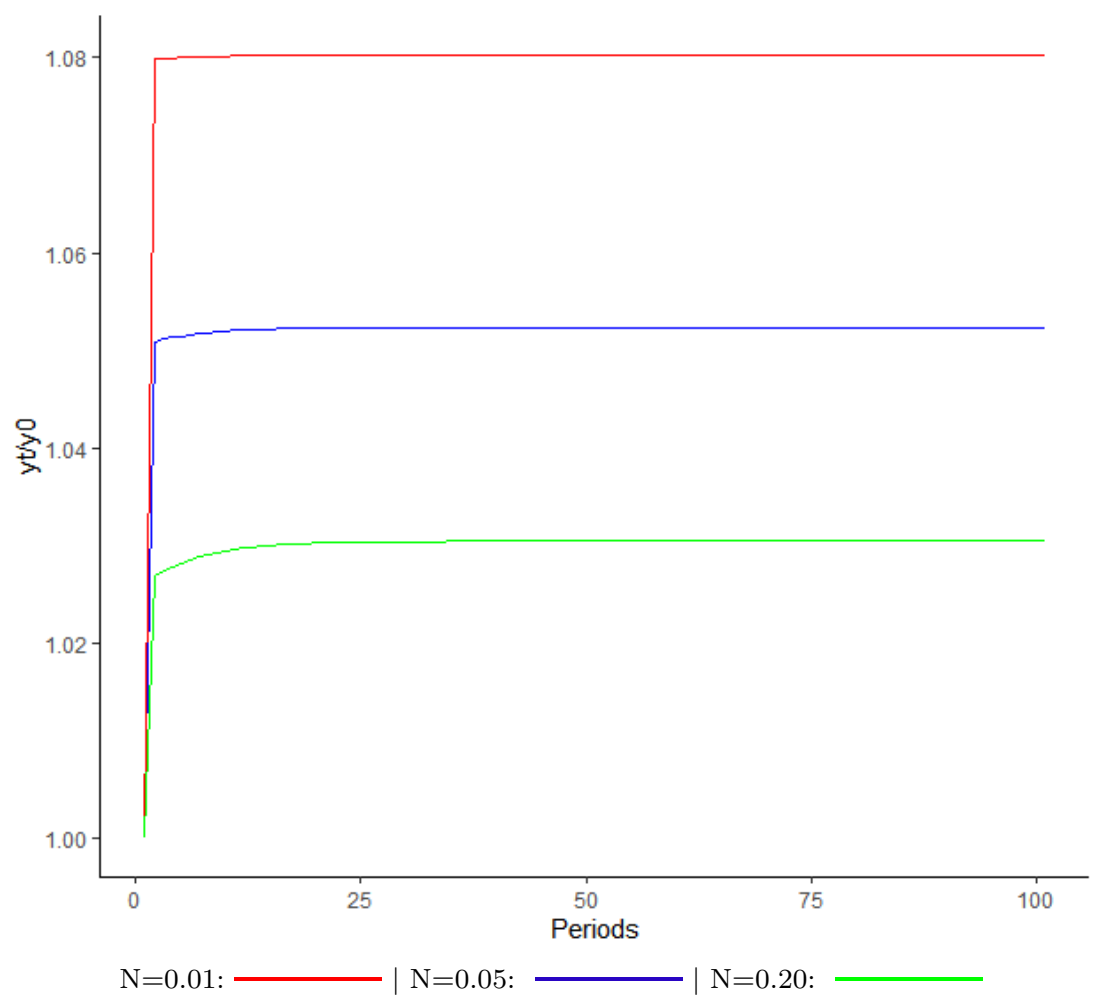

Figure 21 - Transition paths of $y_{t} / y_{0}$ in the open economy 


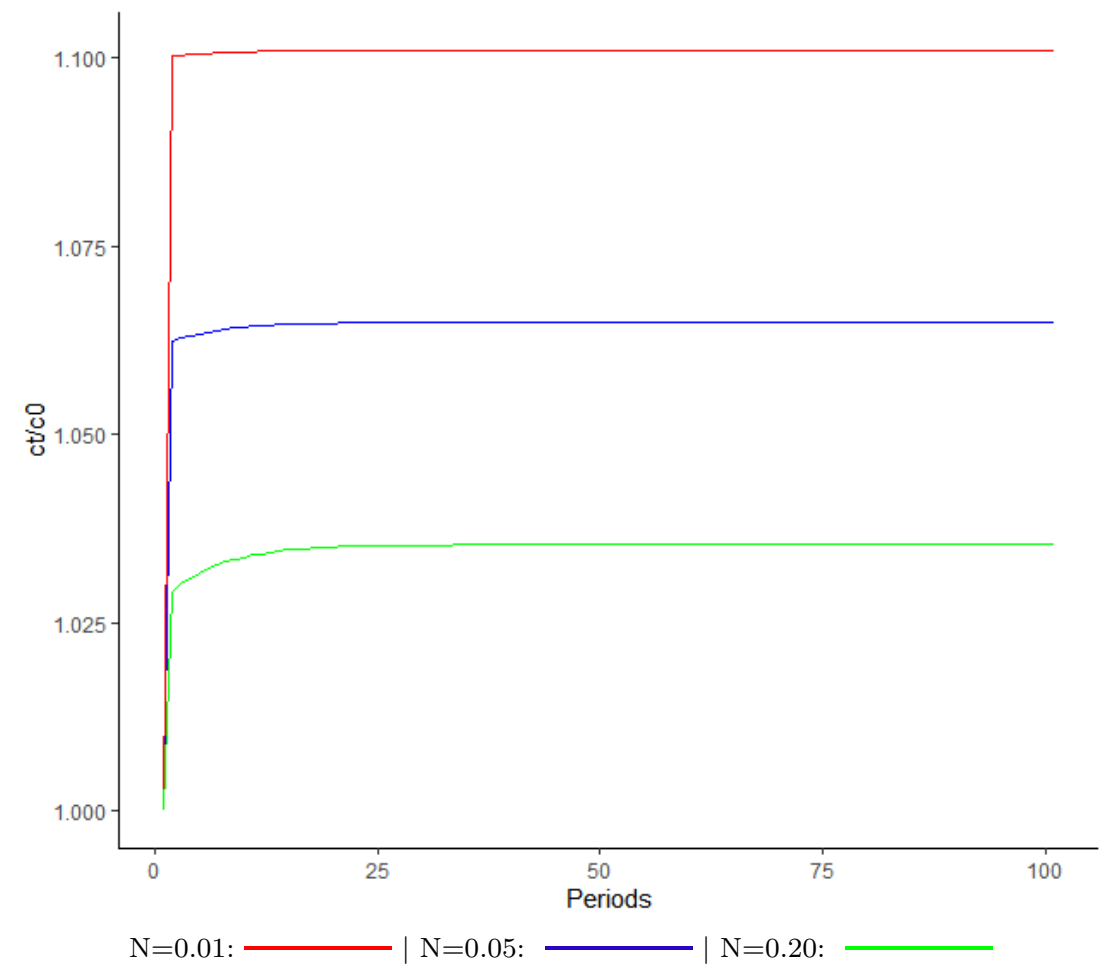

Figure 22 - Transition paths of $c_{t} / c_{0}$ in the open economy

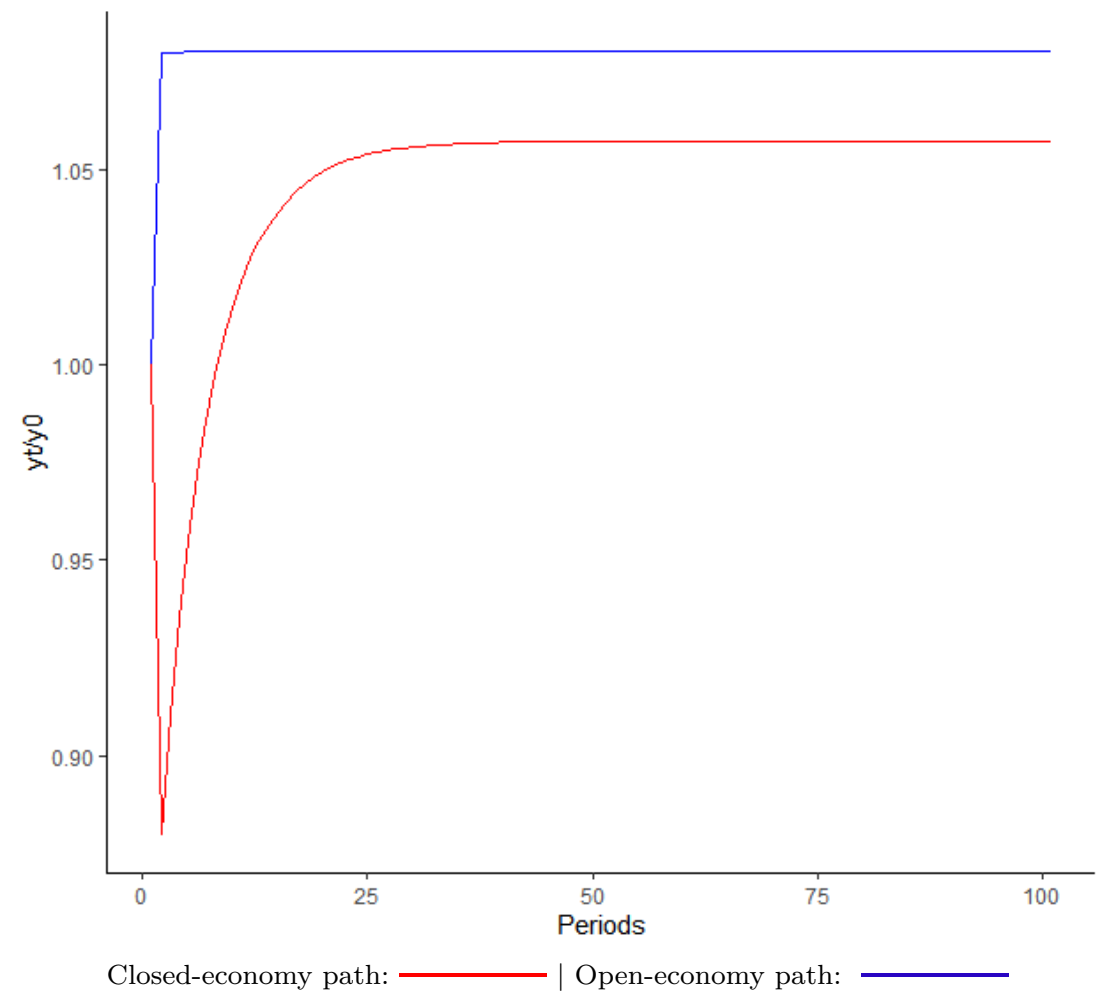

Figure 23 - Transition paths of $y_{t} / y_{0}(\mathrm{~N}=0.01)$ 


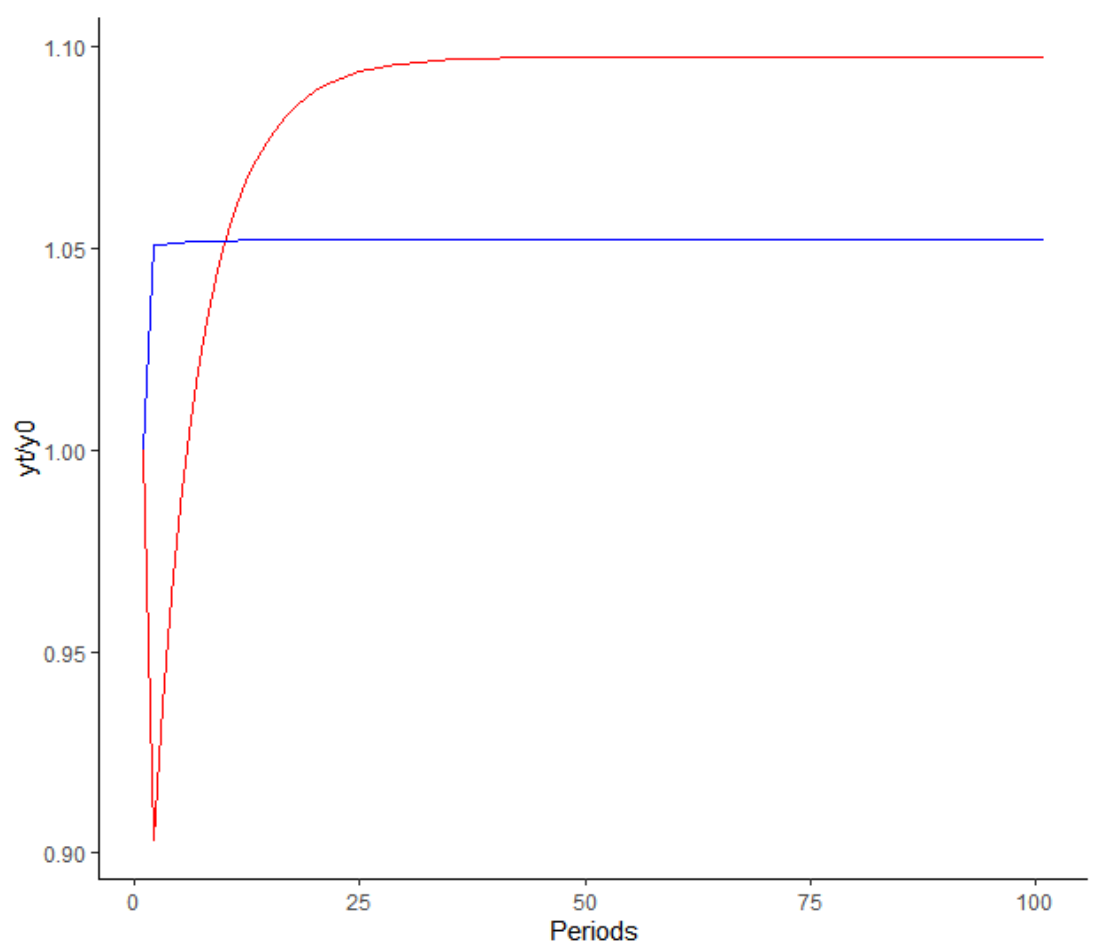

Closed-economy path:

| Open-economy path:

Figure 24 - Transition paths of $y_{t} / y_{0}(\mathrm{~N}=0.05)$

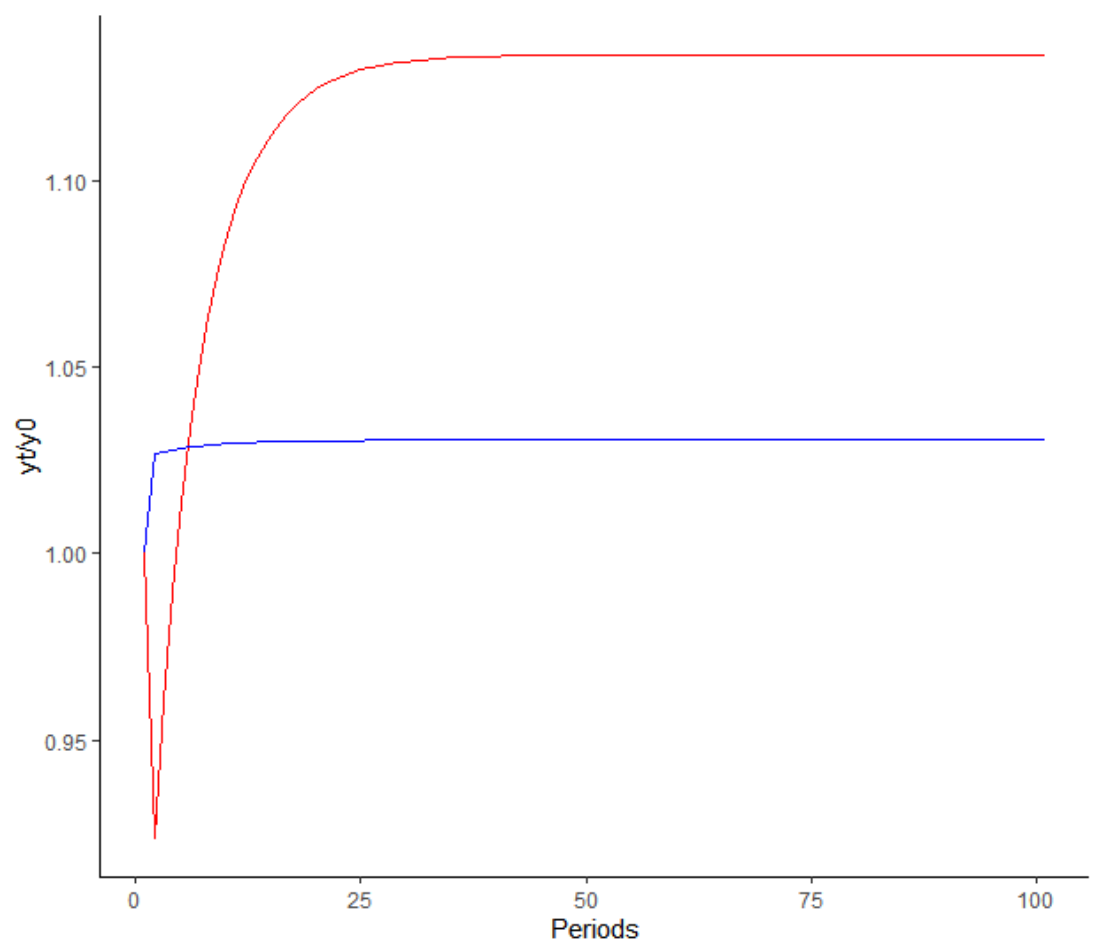

Closed-economy path:

| Open-economy path:

Figure 25 - Transition paths of $y_{t} / y_{0}(N=0.20)$ 


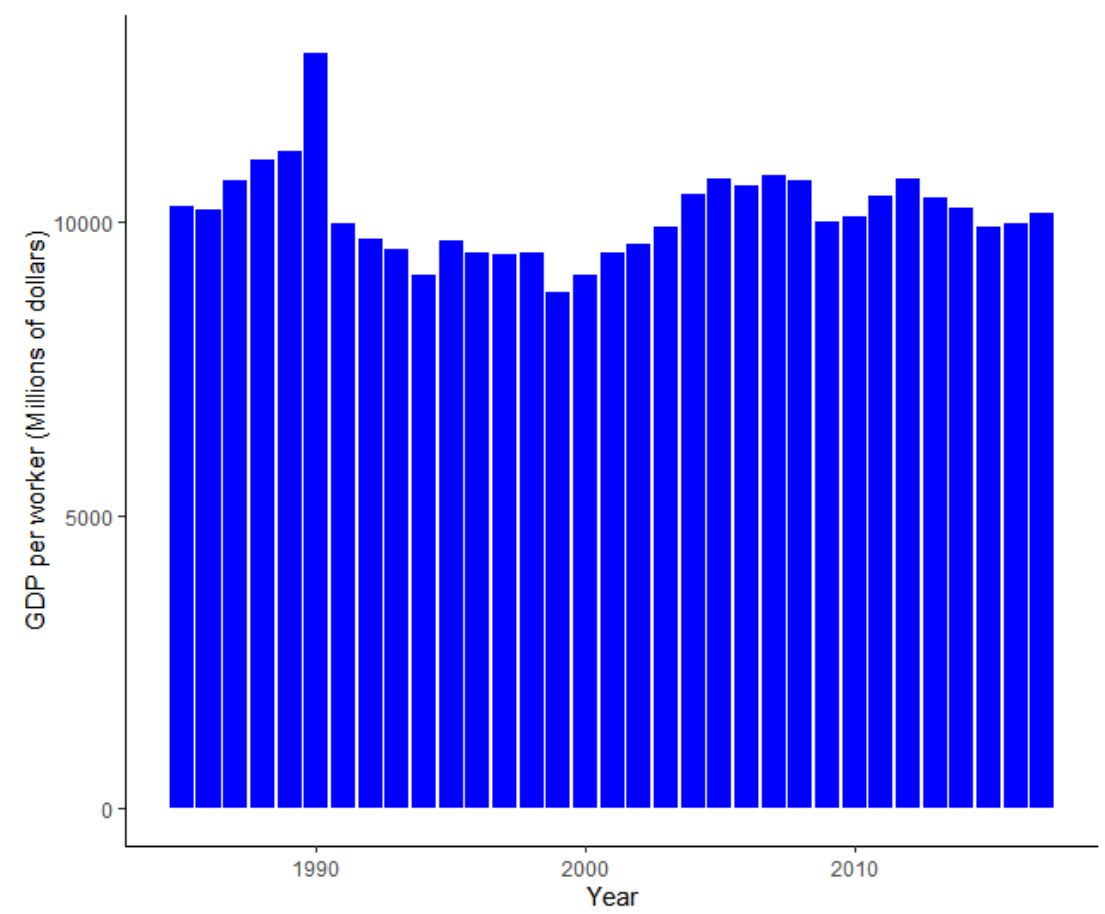

Notes: Data from PWT 9.1 (Feenstra, Inklaar and Timmer (2015)). GDP per worker is PPP adjusted.

Figure 26 - GDP per worker (millions of dollars) of Honduras between 1985 and 2017 